\title{
Local artifacts in ice core methane records caused by layered bubble trapping and in situ production: a multi-site investigation
}

\author{
Rachael H. Rhodes ${ }^{1, a}$, Xavier Fä̈n ${ }^{2}$, Edward J. Brook ${ }^{1}$, Joseph R. McConnell ${ }^{3}$, Olivia J. Maselli ${ }^{3, b}$, Michael Sigl ${ }^{3,4}$, \\ Jon Edwards $^{1}$, Christo Buizert ${ }^{1}$, Thomas Blunier ${ }^{5}$, Jérôme Chappellaz ${ }^{2}$, and Johannes Freitag ${ }^{6}$ \\ ${ }^{1}$ College of Earth, Ocean and Atmospheric Sciences, Oregon State University, Corvallis OR, USA \\ ${ }^{2}$ Université Grenoble Alpes/CNRS, Laboratoire de Glaciologie et Géophysique de l'Environnement, Grenoble, France \\ ${ }^{3}$ Division of Hydrologic Sciences, Desert Research Institute, Reno NV, USA \\ ${ }^{4}$ Laboratory for Radiochemistry and Environmental Chemistry, Paul Scherrer Institut, Villigen, Switzerland \\ ${ }^{5}$ Centre for Ice and Climate, Niels Bohr Institute, University of Copenhagen, Copenhagen, Denmark \\ ${ }^{6}$ Alfred Wegener Institute, Helmholtz Centre for Polar and Marine Research, Bremerhaven, Germany \\ ${ }^{a}$ now at: Department of Earth Sciences, University of Cambridge, Cambridge, UK \\ ${ }^{b}$ now at: Department of Chemistry, University of Adelaide, South Australia, Australia
}

Correspondence to: Rachael H. Rhodes (rhr34@cam.ac.uk)

Received: 5 December 2015 - Published in Clim. Past Discuss.: 15 January 2016

Revised: 15 April 2016 - Accepted: 19 April 2016 - Published: 26 April 2016

\begin{abstract}
Advances in trace gas analysis allow localised, non-atmospheric features to be resolved in ice cores, superimposed on the coherent atmospheric signal. These highfrequency signals could not have survived the low-pass filter effect that gas diffusion in the firn exerts on the atmospheric history and therefore do not result from changes in the atmospheric composition at the ice sheet surface. Using continuous methane $\left(\mathrm{CH}_{4}\right)$ records obtained from five polar ice cores, we characterise these non-atmospheric signals and explore their origin. Isolated samples, enriched in $\mathrm{CH}_{4}$ in the Tunu13 (Greenland) record are linked to the presence of melt layers. Melting can enrich the methane concentration due to a solubility effect, but we find that an additional in situ process is required to generate the full magnitude of these anomalies. Furthermore, in all the ice cores studied there is evidence of reproducible, decimetre-scale $\mathrm{CH}_{4}$ variability. Through a series of tests, we demonstrate that this is an artifact of layered bubble trapping in a heterogeneousdensity firn column; we use the term "trapping signal" for this phenomenon. The peak-to-peak amplitude of the trapping signal is typically $5 \mathrm{ppb}$, but may exceed $40 \mathrm{ppb}$. Signal magnitude increases with atmospheric $\mathrm{CH}_{4}$ growth rate and seasonal density contrast, and decreases with accumulation rate. Significant annual periodicity is present in the $\mathrm{CH}_{4}$ variability of two Greenland ice cores, suggesting that lay-
\end{abstract}

ered gas trapping at these sites is controlled by regular, seasonal variations in the physical properties of the firn. Future analytical campaigns should anticipate high-frequency artifacts at high-melt ice core sites or during time periods with high atmospheric $\mathrm{CH}_{4}$ growth rate in order to avoid misinterpretation of such features as past changes in atmospheric composition.

\section{Introduction}

Continuous measurement of ice core methane $\left(\mathrm{CH}_{4}\right)$ concentrations utilising laser spectroscopy (Stowasser et al., 2012) is rapidly emerging as a powerful tool in palaeoclimatology, producing highly detailed records of atmospheric methane for the Last Glacial Period (Chappellaz et al., 2013; Rhodes et al., 2015) and Late Holocene (Rhodes et al., 2013). The ability to expediently and precisely measure trace gases in ice cores at centimetre-scale depth resolution also allows us to locally resolve novel, high-frequency signals that do not reflect past atmospheric conditions (Faïn et al., 2014; Rhodes et al., 2013) but instead reveal new information about other processes that influence trace gases in ice cores.

The processes of diffusive mixing and gradual bubble close-off, which occur in the firn column, cumulatively act as 
a low-pass filter, removing high-frequency atmospheric signals, such as the $\mathrm{CH}_{4}$ seasonal cycle (Schwander et al., 1993; Trudinger et al., 1997). All polar ice cores therefore yield trace gas records that are smoothed versions of the actual atmospheric history, with the degree of smoothing depending on site conditions, particularly temperature and accumulation rate (Schwander et al., 1997). Although the degree to which any past atmospheric signal is damped by the firn is not always well constrained, it can be estimated (Rosen et al., 2014; Spahni et al., 2003). Trace gas signals present at frequencies above those that could be preserved in the face of the natural smoothing cannot represent atmospheric history. If they are present we must assume that they are not related directly to the original atmospheric variation at the surface of the ice sheet.

A previous study of Late Holocene Greenlandic ice (North Greenland Eemian Project (NEEM)-2011-S1 ice core; Rhodes et al., 2013) identified three categories of nonatmospheric $\mathrm{CH}_{4}$ signals:

1. Infrequent, abrupt $\mathrm{CH}_{4}$ spikes $(20-100 \mathrm{~cm}$ depth interval, 35-80 ppb excess $\mathrm{CH}_{4}$ ) coincident with elevated concentrations of refractory black carbon $(\mathrm{rBC})$ and ammonium $\left(\mathrm{NH}_{4}^{+}\right)$, suggested to be linked to microbial in situ production. Similar amplitude $\mathrm{CH}_{4}$ anomalies, typically coeval with elevated $\mathrm{NH}_{4}^{+}$, were subsequently reported in Greenland Ice Sheet Project 2 (GISP2) Holocene ice (Mitchell et al., 2013). The NEEM Community Members (2013) also implicated biological in situ production in the much larger amplitude (> $1000 \mathrm{ppb}$ ) $\mathrm{CH}_{4}$ anomalies observed in NEEM ice dating from the last interglacial (Eemian).

2. $\mathrm{CH}_{4}$ oscillations of $>100 \mathrm{ppb}$ peak-to-peak amplitude through the lock-in zone. Following Etheridge et al. (1992), it was suggested that the $\mathrm{CH}_{4}$ variability was related to the mechanism of layered bubble trapping (Fig. 1). Briefly, according to this mechanism, air bubbles in relatively dense layers close off earlier, trapping anomalously old air, and air bubbles in less dense layers close off later, trapping relatively young air. Providing that there is a sustained gradient of change in atmospheric methane across this time span, the air bubbles in adjacent layers will contain different concentrations of methane. Mitchell et al. (2015) quantified this phenomenon in samples from the lock-in zone of the West Antarctic Ice Sheet (WAIS)-Divide ice core and developed a parameterisation for layered bubble trapping in a firn densification model.

3. Quasi-annual scale $\mathrm{CH}_{4}$ oscillations of $24 \mathrm{ppb}$ peak-topeak amplitude in the mature ice phase. Such features had only been observed previously in mature ice at Law Dome by Etheridge et al. (1992) who observed $\mathrm{CH}_{4}$ variability consistent with younger air being trapped in summer layers and older air trapped in winter layers.
Although Rhodes et al. (2013) hypothesised that they observed similar features, decimetre-scale $\mathrm{CH}_{4}$ oscillations were observed throughout the NEEM-2011-S1 $\mathrm{CH}_{4}$ record, not only during periods of sustained change in atmospheric $\mathrm{CH}_{4}$ concentration, questioning whether all the resolved variability could be attributed to the layered bubble trapping mechanism.

The findings summarised above generate many questions about what factors affect the biological and/or physical mechanisms responsible for the non-atmospheric $\mathrm{CH}_{4}$ signals in polar glacial ice. For example, is the suspected in situ production of $\mathrm{CH}_{4}$ ubiquitous across the Greenland ice sheet? Can similar anomalous signals be detected in Antarctic ice that has a significantly lower impurity loading? How do site temperature, accumulation rate and impurity load affect the high-frequency $\mathrm{CH}_{4}$ variability tentatively linked to layered bubble close-off?

These questions are critically important because ice core trace gas records are integral to palaeoclimatology, enabling us to investigate the relationship between atmospheric greenhouse gases and climate prior to the late 20th century. Recent analytical advances in both discrete (Mitchell et al., 2011) and continuous trace gas measurement techniques (Rhodes et al., 2013; Stowasser et al., 2012) have increased data precision and resolution, which is undoubtedly advantageous for palaeoclimate research, but also increases the likelihood of resolving non-atmospheric signals. Avoiding misinterpretation of non-atmospheric signals and therefore having confidence in the fidelity of the atmospheric histories constructed from ice cores requires detailed knowledge of the physical and biological processes that may locally affect trace gas records. This knowledge, acquired from polar ice cores, could also provide hints about how to extract an atmospheric signal from gas measurements performed on non-polar ice cores that are significantly affected by such artifacts (e.g., Hou et al., 2013). Furthermore, by studying non-atmospheric artifacts in ice core gas records we may learn about the physical mechanisms which trap air bubbles in the firn enabling us to improve numerical model parameterisations used to estimate the gas age-ice age difference and the smoothing effect of firn-based processes. Additionally, it may be possible to glean information about biological activity in one of the harshest biomes on Earth (Rohde et al., 2008).

This study examines Late Holocene $\mathrm{CH}_{4}$ records with centimetre-scale resolution from five polar ice cores with contrasting site characteristics (Table 1). Four of the cores are from Greenland and one is from East Antarctica (Fig. S1 in the Supplement). Accumulation rate and temperature, the principal factors affecting firn densification rates, vary considerably between the different cores. Concentrations of chemical impurities contained within the ice can also vary by an order of magnitude (Table 1). Here we compare the ultra-high-resolution $\mathrm{CH}_{4}$ records of the five different ice cores to show that the high-frequency non-atmospheric sig- 
Table 1. Locations, site characteristics and other relevant information for ice cores featured in this study. Please refer to footnotes for explanation of abbreviations.

\begin{tabular}{|c|c|c|c|c|c|c|c|}
\hline $\begin{array}{l}\text { Ice core \& } \\
\text { location } \\
\text { (see map Fig. S1) }\end{array}$ & $\begin{array}{l}\text { Depth } \\
\text { interval } \\
\text { (m) }\end{array}$ & $\begin{array}{l}\text { Gas age } \\
\text { interval } \\
\text { (yr AD) }\end{array}$ & $\begin{array}{l}\Delta \text { age } \\
\text { and FWHM } \\
\text { (yr) }\end{array}$ & $\begin{array}{l}\text { Accum. } \\
\text { rate } \\
\left(\mathrm{cm}_{\text {ice }} \mathrm{yr}^{-1}\right)\end{array}$ & $\begin{array}{l}\text { Mean } \\
\text { annual temp. } \\
\left({ }^{\circ} \mathrm{C}\right)\end{array}$ & $\begin{array}{l}\text { Mean } \\
\text { liq. cond. } \\
(\mu S)\end{array}$ & Age scale \\
\hline $\begin{array}{l}\text { B40 } \\
\text { Drønning Maud Land } \\
\text { E. Antarctica } \\
75.001^{\circ} \mathrm{S}, 0.068^{\circ} \mathrm{E} \\
2911 \mathrm{~m} \text { elevation }\end{array}$ & $200-88$ & $331-1710$ & $\begin{array}{l}811 \\
65\end{array}$ & $6.8^{\mathrm{b}}$ & $-46^{\mathrm{b}}$ & 1.33 & $\begin{array}{l}\text { Ice: ALC+VS } \\
\text { Gas: tied to } \\
\text { WDC06A-7 }\end{array}$ \\
\hline $\begin{array}{l}\text { D4 } \\
\text { S. Central Greenland } \\
71.40^{\circ} \mathrm{N}, 43.08^{\circ} \mathrm{W} \\
2713 \text { m elevation }\end{array}$ & 146-61 & $1825-1961$ & $\begin{array}{l}90 \\
14\end{array}$ & 41 & -24 & 101 & $\begin{array}{l}\text { Ice: ALC+VS } \\
\text { Gas: tied to } \\
\text { WDC06A-7 }^{\mathrm{f}} \\
\text { \& Law Dome }\end{array}$ \\
\hline $\begin{array}{l}\text { NEEM } \\
\text { NW Greenland } \\
77.45^{\circ} \mathrm{N}, 51.06^{\circ} \mathrm{W} \\
2450 \mathrm{~m} \text { elevation }\end{array}$ & 573-399 & $-682-322$ & $\begin{array}{l}187^{\mathrm{a}} \\
17\end{array}$ & $22^{\mathrm{c}}$ & $-28.9^{c}$ & 122 & $\begin{array}{l}\text { Ice: } \mathrm{GICC} 05^{\mathrm{h}} \\
\text { Gas: GICC0 } 05^{\mathrm{h}}\end{array}$ \\
\hline $\begin{array}{l}\text { NGRIP } \\
\text { Central Greenland } \\
75.10^{\circ} \mathrm{N}, 42.32^{\circ} \mathrm{W} \\
2917 \mathrm{~m} \text { elevation }\end{array}$ & $\begin{array}{l}569-519 \\
254-207 \\
108-74\end{array}$ & $\begin{array}{l}-929-616 \\
980-1237 \\
1780-1926\end{array}$ & $\begin{array}{l}235 \\
18\end{array}$ & $19^{d}$ & $-31.5^{\mathrm{d}}$ & $\begin{array}{l}122 \\
105 \\
107\end{array}$ & $\begin{array}{l}\text { Ice: } \mathrm{GICC} 05^{\mathrm{h}} \\
\text { Gas: tied to } \\
\text { WDC06A-7 }\end{array}$ \\
\hline $\begin{array}{l}\text { Tunu13 } \\
\text { NE Greenland } \\
78.035^{\circ} \mathrm{N}, 33.879^{\circ} \mathrm{W} \\
2200 \mathrm{~m} \text { elevation }\end{array}$ & $213-73$ & $836-1893$ & $\begin{array}{l}314-369 \\
21-27\end{array}$ & $10-14$ & $-29^{\mathrm{e}}$ & 115 & $\begin{array}{l}\text { Ice: } \mathrm{ALC}+\mathrm{VS} \mathrm{S}^{\mathrm{i}} \\
\text { Gas: tied to } \\
\text { WDC06A- }^{\mathrm{f}}\end{array}$ \\
\hline $\begin{array}{l}\text { WAIS Divide } \\
\text { West Antarctica } \\
79.47^{\circ} \mathrm{S}, 112.08^{\circ} \mathrm{W} \\
1766 \mathrm{~m} \text { elevation }\end{array}$ & $\mathrm{n} / \mathrm{a}$ & $\mathrm{n} / \mathrm{a}$ & $208^{\mathrm{j}}$ & $20^{\mathrm{j}}$ & $-31^{\mathrm{j}}$ & $\mathrm{n} / \mathrm{a}$ & $\mathrm{n} / \mathrm{a}$ \\
\hline
\end{tabular}

Note: $\Delta$ age $=$ difference between gas age and ice age. If no reference is provided, value is estimated by age scale synchronisation or OSU firn air model; FWHM $=$ Full Width at Half Maximum of gas age distribution at close-off depth estimated by OSU firn air model (Rosen et al., 2014); mean liq. cond. = mean liquid conductivity; $\mathrm{ALC}=$ annual layer count; VS = volcanic synchronisation; gas age scales do not incorporate lock-in zone measurements. ${ }^{\mathrm{a}}$ Buizert et al. $(2014) ;{ }^{\mathrm{b}}$ Klein $(2014) ;{ }^{\mathrm{c}}$ NEEM community members (2013); ${ }^{\mathrm{d}}$ NGRIP community members (2004); ${ }^{\mathrm{e}}$ Butler et al. (1999); ${ }^{\mathrm{f}}$ Mitchell et al. (2013); ${ }^{\mathrm{g}}$ MacFarling Meure et al. (2006); ${ }^{\mathrm{h}}$ Rasmussen et al. (2013); ${ }^{\mathrm{i}}$ Sigl et al. (2015); ${ }^{\mathrm{j}}$ Mitchell et al. (2011).

nals we previously observed in NEEM-2011-S1 ice are not unique to this site. Furthermore, we demonstrate how several site characteristics influence the frequency and magnitude of non-atmospheric signals.

\section{Methods}

\subsection{Sample description}

The ice core samples analysed in this study are listed in Table 1. Archived samples were obtained from NEEM, D4 and North Greenland Ice Core Project (NGRIP). The NEEM section was chosen to extend the existing NEEM-2011-S1 record further back in time. The D4 record extends the NEEM-2011-S1 record forward in time and is from a warmer Greenland site with twice the accumulation rate. The NGRIP samples are from two Late Holocene depth intervals. A new ice core was retrieved from Tunu, NE Greenland, where accumulation rates are about half those of NEEM or NGRIP. Hereafter the Tunu core will be referred to as Tunu13 to avoid confusion with previous drilling projects. Two Tunu13 cores were drilled: the first (Tunu13 Main) extended from the surface to $214 \mathrm{~m}$ depth and the second (Tunu13 B) from the surface to $140 \mathrm{~m}$ depth. The continuous gas and chemistry records used in this study are predominantly from the Tunu13 Main core with sections of Tunu13 B spliced in where poor core quality of Tunu13 Main core caused deterioration of the records (see Supplement). Prior to analysis, the Tunu13 cores were logged at the National Ice Core Laboratory. Bottom depths of bubble-free layers were recorded and top depths were recorded if the layer's width exceeded $4 \mathrm{~mm}$. It was not possible to discriminate visually between bubble- 

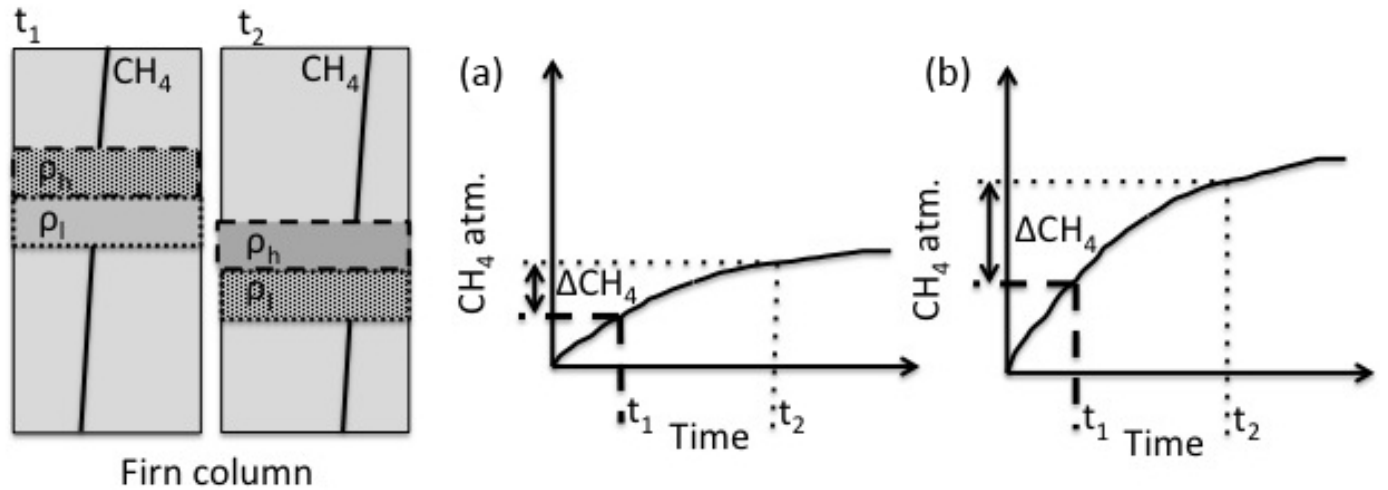

Figure 1. Schematic to illustrate how the layered bubble trapping mechanism can generate high-frequency $\mathrm{CH}_{4}$ artifacts in ice cores. At time $t_{1}$, air bubbles within the relatively high-density $\left(p_{\mathrm{h}}\right)$ layer are closed off at a relatively shallow depth in the firn column. At time $t_{2}$, air bubbles with the relatively low-density $\left(p_{1}\right)$ layer are closed off deeper in the firn column. Between $t_{1}$ and $t_{2}$ the atmospheric concentration of $\mathrm{CH}_{4}$ is increasing and so the $\mathrm{CH}_{4}$ concentration in the diffusive column also increases, generating a $\mathrm{CH}_{4}$ concentration difference $\Delta \mathrm{CH}_{4}$ between the bubbles in depth-adjacent layers trapped at $t_{1}$ and $t_{2}$. Increasing the atmospheric $\mathrm{CH}_{4}$ growth rate (b compared to a) results in a larger $\Delta \mathrm{CH}_{4}$. A negative atmospheric growth rate would cause a change in the sign of $\Delta \mathrm{CH}_{4}$.

free layers that were melt layers and those that were wind crusts (fine-grained, sintered layers thought to result from wind action (Alley, 1988). Both are likely to occur as Tunu is a windy site and our field team found melt layers from the 2012 Greenland melt event. The B40 ice core was drilled close to Kohnen Station, Dronning Maud Land, E Antarctica, by the Alfred Wegner Institute and represents the coldest site with lowest impurity loading of the cores featured in this study (Table 1).

\subsection{Analytical methods}

All the ice cores listed in Table 1 were analysed at the Desert Research Institute, Reno NV, USA, using a continuous ice core melter system with online gas measurements (Rhodes et al., 2013, 2015). Chemical concentrations in the liquid were measured simultaneously, as described previously (McConnell et al., 2002, 2007).

An optical feedback cavity enhanced absorption spectrometer (SARA, developed at Laboratoire Interdisciplinaire de Physique, University Grenoble Alpes, Grenoble, France; Morville et al., 2005) was used to analyse methane - the same instrument as used by Rhodes et al. (2013) and Faïn et al. (2014). The system response time (time to reach $90 \%$ of concentration step change; $t_{90}$ ) was $109 \mathrm{~s}$, equivalent to 9.4-12.3 cm, depending on the melt rate used for each ice core (Table S1). Methane data were corrected for dissolution in the melted ice core sample following methods described previously (Rhodes et al., 2013). Some system parameters, such as melt rate, varied between ice cores to ensure the best compromise between measurement efficiency and resolution (mainly in liquid phase) and different solubility corrections are used to account for this (Table S1). Allan variance tests performed on measurements of synthetic sample (standard gas mixed with degassed water) suggested an optimal inte- gration time $>1000 \mathrm{~s}$. However, to maximise depth resolution we used an integration time of $5 \mathrm{~s}$, for which Allan variance tests suggest an internal precision of $1.7 \mathrm{ppb}(2 \sigma)$.

To limit entry of ambient air into the analytical system as breaks in the core were encountered, ice was removed at any angled breaks to obtain a planar surface on which the next ice stick could sit squarely. This resulted in some short sections of data loss. Methane data were manually screened for spikes resulting from ambient air entry at the melterhead (see also Sect. 3.2) because an automated screening algorithm proved too aggressive, resulting in the removal of real variability, as confirmed by discrete $\mathrm{CH}_{4}$ measurements.

Methane and chemistry data were mapped onto a depth scale using high-resolution $(0.1-0.5 \mathrm{~Hz}$ acquisition rate) liquid conductivity data and time-depth relationships recorded by system operators. A constant melt rate for each metre length of core is assumed. Depth scale uncertainties are estimated to be $\pm 2 \mathrm{~cm}(2 \sigma)$. The ice and gas age scales used for each ice core are listed in Table 1.

For comparison, discrete samples from the Tunu13 ice core were analysed at Oregon State University for methane concentration and total air content. Minor adjustments to the methods of Mitchell et al. (2011) are described in the Supplement. Twenty-four $\sim 15 \mathrm{~cm}$ depth sections were analysed at $6 \mathrm{~cm}$ resolution. External precision of these data, estimated as pooled standard deviation of 34 duplicate (horizontallyadjacent) sample sets, is $3.1 \mathrm{ppb}$ for $\mathrm{CH}_{4}$ and $0.002 \mathrm{~cm}^{3} \mathrm{STP}$ $\mathrm{g}^{-1}$ ice for total air content $(1 \sigma)$.

\subsection{Firn air transport models}

We compare our empirical data to theoretical model predictions of $\mathrm{CH}_{4}$ concentrations in closed bubbles resulting from layered gas trapping produced by the Center for Ice and Climate (CIC), Copenhagen, firn air transport model (Buizert et 

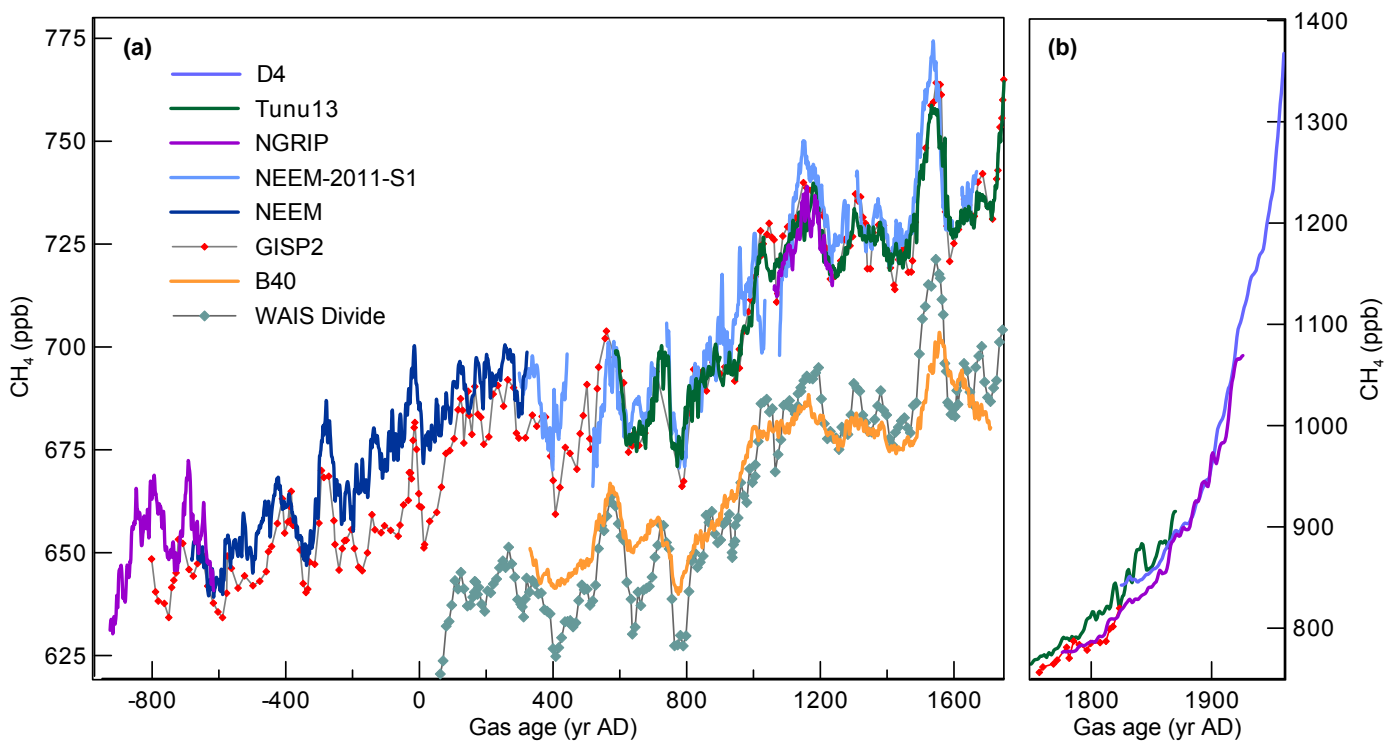

Figure 2. Late Holocene continuous $\mathrm{CH}_{4}$ data from Tunu13, D4, NGRIP and NEEM Greenland ice cores and B40 Antarctic ice core for time periods -900-1750 AD (a) and 1750-1960 AD (b). Each record is a cubic spline fit with 1-year sample spacing to the $5 \mathrm{~s}$ integrated data. No data from the lock-in zone are included on this figure. Also plotted are discrete $\mathrm{CH}_{4}$ data from GISP2 and WAIS Divide ice cores (Mitchell et al., 2013) and NEEM-2011-S1 continuous $\mathrm{CH}_{4}$ data (Rhodes et al., 2013).

al., 2012). This model includes parameterisation of stochastic gas trapping related to local density variability (Mitchell et al., 2015). All experiments are run for the WAIS Divide ice core site because high-resolution local density data are available, as well as firn air sample data needed to calibrate the diffusivity profile in the open pores. Model simulations are performed at $1 \mathrm{~cm}$ vertical resolution to accurately capture the influence of layered bubble trapping. Further details on modelling centimetre-scale air occlusion are provided by Mitchell at al. (2015). The model simulations for the WAIS Divide ice core site can be compared to Greenland ice core sites because the site conditions, particularly temperature and accumulation rate, are relatively similar (Table 1).

In addition, we use the Oregon State University (OSU) firn air transport model (Buizert et al., 2012), adapted for palaeoapplications (Rosen et al., 2014), to estimate the smoothing effect that gas diffusion in the firn has on the $\mathrm{CH}_{4}$ atmospheric history at each ice core site (Fig. S2).

\section{Results and discussion}

\subsection{Integrity of the atmospheric $\mathrm{CH}_{4}$ history from ice cores}

Multi-decadal scale atmospheric $\mathrm{CH}_{4}$ variability, previously observed in Law Dome DSS (MacFarling Meure et al., 2006), WAIS Divide (Mitchell et al., 2011), GISP2 (Mitchell et al., 2013) and NEEM-2011-S1 (Rhodes et al., 2013), is faithfully replicated in all the ice cores analysed in this study (Fig. 2). The multi-decadal signals recorded in each core vary in amplitude because the original atmospheric signal has been smoothed to a different extent at each site by firnbased processes (diffusive mixing and gradual bubble occlusion). As expected, the low accumulation, cold, East Antarctic core B40 exhibits the most extreme firn-based smoothing (orange line), and the Tunu 13 record (green line) shows significant signal damping compared to NGRIP (purple line) due to the lower accumulation rates at Tunu. The estimated gas age distribution width (full width at half maximum) at close-off depth for present-day conditions at each ice core site ranges from 14 years at D4 to 65 years at B40 (Table 1). Atmospheric signals of a shorter period than the gas age distribution width are unlikely to be resolved with their full amplitude in the ice core record.

\subsection{Potential in situ $\mathrm{CH}_{4}$ production and melt layers}

The continuous $\mathrm{CH}_{4}$ records of all the ice cores analysed contained a high-frequency component superimposed on the coherent atmospheric signals shown in Fig. 2. For this study it was particularly challenging to confidently distinguish between isolated anomalously high $\mathrm{CH}_{4}$ spikes present in situ and those resulting from contamination by ambient air. Forest fire haze over Reno during the analytical campaign meant that it was not possible to rely on the absence of a carbon monoxide (CO) signal as indicative of ambient air entry, as has previously been the case (Rhodes et al., 2013). This problem was compounded by poor core quality (high break density, Table S1) in some core sections. However, in a limited number of cases, discussed below, we were able to distinguish between ambient air contamination and in situ $\mathrm{CH}_{4}$ signals. 


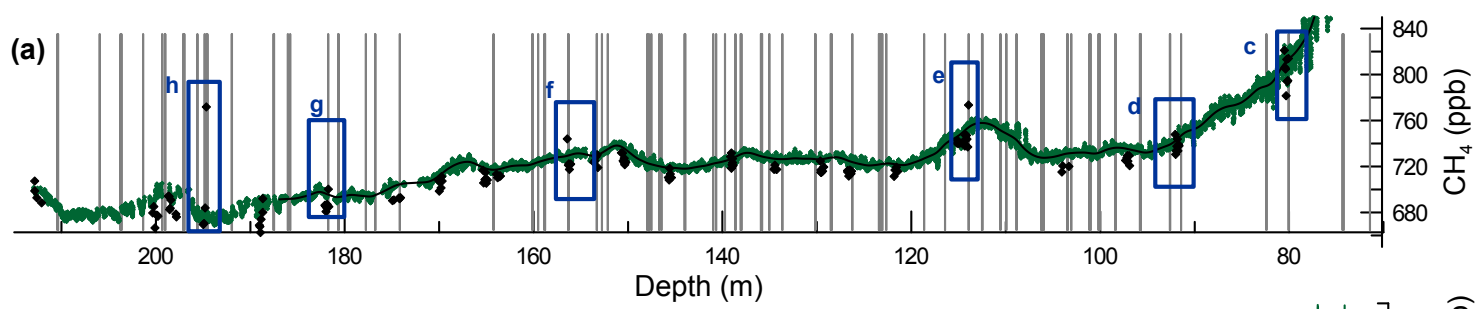

(b)
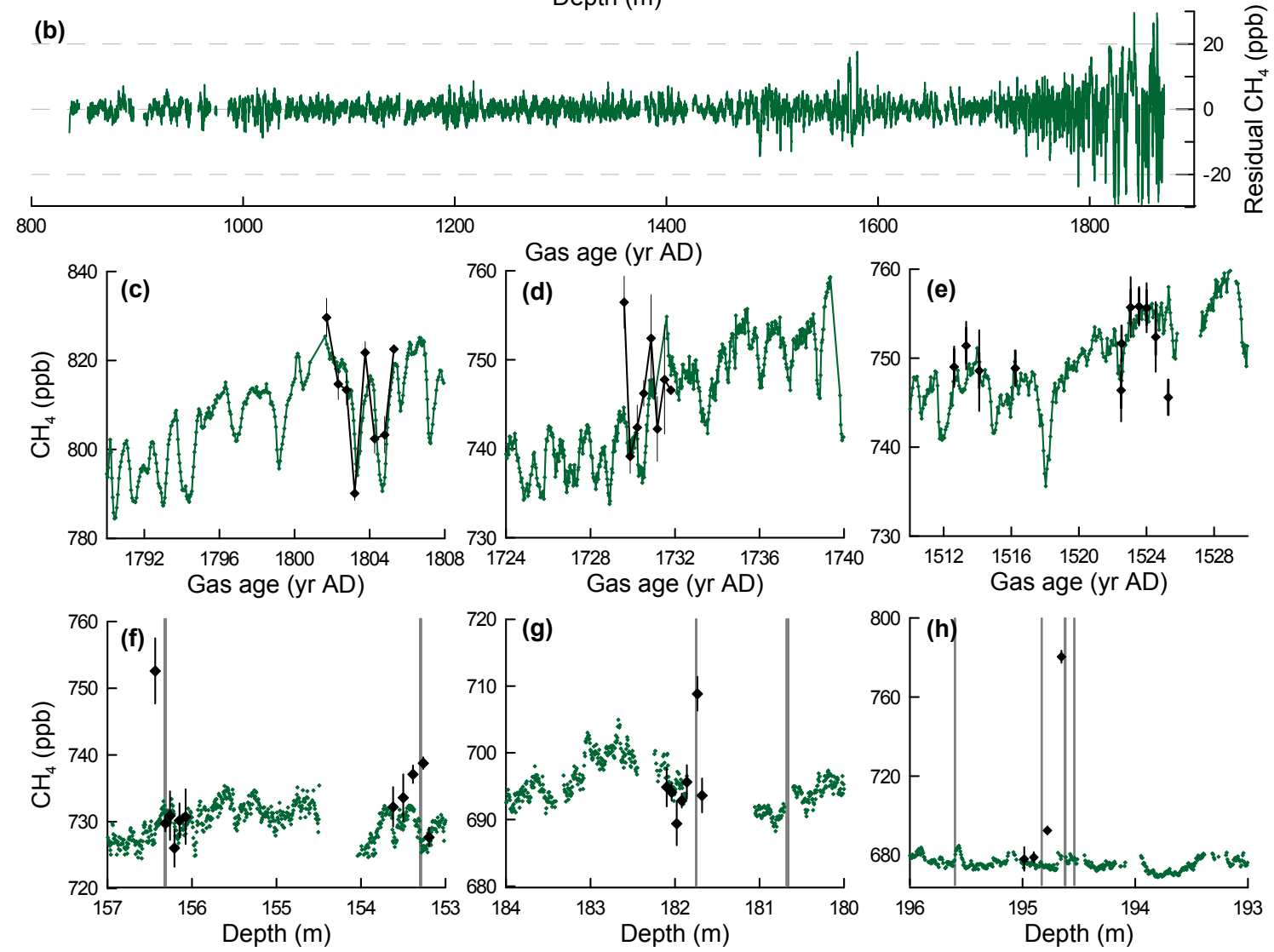

Figure 3. Decimetre-scale $\mathrm{CH}_{4}$ variability in Tunu13 mature ice captured by continuous (green) and discrete (black diamonds) analyses: (a) both records on depth scale with vertical grey lines indicating depths of bubble-free layers observed; (b) residual high-frequency nonatmospheric component of Tunu13 signal: continuous record (green on panel a) minus cubic spline fit (black line on panel a). Data from below $172 \mathrm{~m}$ depth are excluded because there are too many data gaps resulting from poor core quality. $Y$ axis has been clipped at -30 and +30 ppb. Data minimum and maximum are -38 and $36 \mathrm{ppb} ; \mathbf{c}-\mathbf{h}$ ) Zoomed views of high-frequency $\mathrm{CH}_{4}$ variability within blue rectangles displayed on panel (a). $\mathrm{CH}_{4}$ concentrations of discrete data points are increased by $8.5 \mathrm{ppb}$ on panels (c)-(h) to aid comparison with continuous data. $2 \sigma$ internal precision uncertainty bars are plotted for discrete data. Horizontal bars on discrete measurements represent depth interval of each sample. Depth uncertainty for the continuous data is estimated to be $\pm 2 \mathrm{~cm}(2 \sigma)$.

Discrete $\mathrm{CH}_{4}$ measurements performed on Tunu13 ice provided useful information concerning isolated in situ $\mathrm{CH}_{4}$ spikes. The $\mathrm{CH}_{4}$ concentrations of 5 of the 146 discrete samples analysed (Table 2) were anomalously high, between 15 and $80 \mathrm{ppb}$ greater than adjacent samples. The elevated $\mathrm{CH}_{4}$ samples also had relatively low air content values of $0.0847-$ $0.0970 \mathrm{~cm}^{3} \mathrm{STP} \mathrm{g}^{-1}$ ice compared to median of $0.1002 \mathrm{~cm}$ STP g ${ }^{-1}$ ice (Table 2), negating the possibility of sample contamination by an ambient air leak during analysis. The five anomalous samples were all located within $2.5 \mathrm{~cm}$ of bubblefree layers logged during processing (Fig. 3a, f-g, Table S2).
We therefore hypothesize that these bubble-free layers are melt layers. Anomalously high $\mathrm{CH}_{4}$ values in ice cores have been linked to melt layers because (a) the solubility of $\mathrm{CH}_{4}$ in water is greater than that of bulk air, and/or (b) previous studies suggest a potential for $\mathrm{CH}_{4}$ production by microbial activity, via reaction pathways that are currently unknown (Campen et al., 2003; NEEM community members, 2013).

The $\mathrm{CH}_{4}$ concentration and air content of each of these discrete samples represent a mixture of air from standard bubbly ice and air from a melt layer. Each discrete sample typically spanned $6 \mathrm{~cm}$ of ice core depth and, by com- 
Table 2. Discrete $\mathrm{CH}_{4}$ and total air content measurements on Tunu13 samples containing melt layers. Estimated $\mathrm{CH}_{4}$ concentrations of the melt layers result from a simple mixing calculation using air content measurements made on Summit melt layer samples. Values in parentheses reflect the range of melt layer air content values measured. Predicted $\mathrm{CH}_{4}$ values are calculated using the assumption that the melt layer was in equilibrium with the atmosphere, according to Henry's Law $\left(0{ }^{\circ} \mathrm{C}, 0.750\right.$ atm. $)$. Henry's Law constants for $\mathrm{CH}_{4}$, $\mathrm{O}_{2}$ and $\mathrm{N}_{2}$ were obtained from NIST Chemistry WebBook (http://webbook.nist.gov/cgi/cbook.cgi?Name=methane\&Units=SI\&cSO=on). $\mathrm{CH} 4$ concentrations of adjacent samples are used as atmospheric concentrations at time of melt layer formation. All of these samples are from the Tunu13 Main core.

\begin{tabular}{|c|c|c|c|c|c|c|c|}
\hline $\begin{array}{l}\text { Sample } \\
\text { depth } \\
\text { range }(m)\end{array}$ & $\begin{array}{r}\text { Sample } \\
\mathrm{CH}_{4} \text { conc. } \\
(\mathrm{ppb})\end{array}$ & $\begin{array}{r}\text { Sample total } \\
\text { air content } \\
\left(\mathrm{cm}^{3} \mathrm{~g}^{-1} \text { ice STP }\right)\end{array}$ & $\begin{array}{l}\text { Melt layer } \\
\text { thickness } \\
(\mathrm{mm})\end{array}$ & $\begin{array}{r}\text { Estimated } \mathrm{CH}_{4} \\
\text { conc. of melt } \\
\text { layer (ppb) }\end{array}$ & $\begin{array}{r}x \text { fold } \mathrm{CH}_{4} \\
\text { enrichment of } \mathrm{ML} \\
\text { relative to sample }\end{array}$ & $\begin{array}{r}\text { Mean } \mathrm{CH}_{4} \\
\text { conc. of adjacent } \\
\text { samples (ppb) }\end{array}$ & $\begin{array}{r}\text { Predicted } \mathrm{CH}_{4} \\
\text { conc. of melt layer in } \\
\text { equilib. with atmos. (ppb) }\end{array}$ \\
\hline $\begin{array}{l}113.910- \\
113.970\end{array}$ & 773.6 & 0.0956 & $\begin{array}{c}4.0 \\
(4781-9940)\end{array}$ & 6355 & 8.6 & 737.1 & 1492 \\
\hline $\begin{array}{l}153.225- \\
153.300\end{array}$ & 730.3 & 0.0859 & $\begin{array}{c}4.0 \\
(1519-2533)\end{array}$ & 1829 & 2.5 & 723.9 & 1465 \\
\hline $\begin{array}{l}156.235- \\
156.285\end{array}$ & 744.1 & 0.0941 & $\begin{array}{c}4.0 \\
(4076-8356)\end{array}$ & 5356 & 7.4 & 721.0 & 1460 \\
\hline $\begin{array}{l}181.710- \\
181.760\end{array}$ & 700.3 & 0.0970 & $\begin{array}{c}4.0 \\
(2020-3721)\end{array}$ & 2539 & 3.7 & 686.1 & 1389 \\
\hline $\begin{array}{l}194.610- \\
194.700\end{array}$ & 771.9 & 0.0847 & $\begin{array}{c}24.0 \\
(2842-5596)\end{array}$ & 3683 & 5.4 & 684.0 & 1385 \\
\hline
\end{tabular}

parison, the melt layers in the Tunu13 cores were very thin, typically spanning $<5 \mathrm{~mm}$ depth. Given that we know the dimensions of each sample and the proportion of the sample volume occupied by the melt layer, we can estimate the $\mathrm{CH}_{4}$ concentration in the melt layer itself (Table 2). We assume that the air content of each melt layer is $0.0095 \pm 0.0037 \mathrm{~cm}^{3} \mathrm{STP} \mathrm{g}^{-1}$ ice ( $1 \sigma$ uncertainty, $n=12$ ), which is the value measured at Oregon State University on melt layer samples (from the 2012 melt event) collected at Summit, Greenland. Estimated melt layer $\mathrm{CH}_{4}$ concentrations range from $1829(+704 /-310)$ ppb to $6355(+3585 /-$ 1574) ppb, equivalent to $2.5-8.6$ fold the atmospheric $\mathrm{CH}_{4}$ concentrations at the time of melt layer formation (Table 2). We then calculate the predicted $\mathrm{CH}_{4}$ concentration of the melt layers if dissolution of $\mathrm{CH}_{4}$ from the atmosphere in liquid water reached equilibrium (Table 2). Methane becomes relatively enriched in liquid water that is in equilibrium with the atmosphere because methane is more soluble than nitrogen (Sander, 2015). The predicted equilibrium $\mathrm{CH}_{4}$ concentrations are all significantly lower than our estimated melt layer concentrations, suggesting that another process, in addition to dissolution, must contribute to the enrichment of $\mathrm{CH}_{4}$ in melt layers. Our findings therefore support those of the NEEM Community Members (2013), who found elevated $\mathrm{CH}_{4}$ concentrations in excess of Henry's Law predictions across a melt layer in the Dye-3 (Greenland) ice core, and also those of Campen et al. (2003), who measured anomalously high $\mathrm{CH}_{4}$ values that could not be explained by dissolution effects alone. We note that in this study we had to infer the $\mathrm{CH}_{4}$ concentration of the melt layer because we were not able to obtain a sample of pure melt layer, and the $\mathrm{CH}_{4}$ values we estimate are relatively uncertain.

In light of this apparent link between anomalously high $\mathrm{CH}_{4}$ concentrations and melt layers in Tunu13 ice, we re- examined the continuous $\mathrm{CH}_{4}$ data and identified a further 14 bubble-free layers, coincident in depth with anomalous $\mathrm{CH}_{4}$ spikes, that we assume are melt layers (Table S2). The onset of these events can be extremely abrupt, making them appear similar to ambient air contamination. Twelve bubblefree layer depths had no continuous $\mathrm{CH}_{4}$ data, usually because data had been removed due to mixing with standard at start/end of a run or because the ice had been removed across a badly-shaped break. The $\mathrm{CH}_{4}$ record at a further 20 bubble-free layer depths was affected by ambient air contamination. There are also 78 bubble-free layer depths for which the $\mathrm{CH}_{4}$ record appears anomaly-free, suggesting that many of these observed bubble-free layers could be wind crusts, not melt layers (Orsi et al., 2015). Alternatively, many of these bubble-free layers did not span the entire horizontal area of the $10 \mathrm{~cm}$ diameter core and may have not have been included in the $3.4 \times 3.4 \mathrm{~cm}$ melter stick cut from the core.

We investigated the chemical composition (nitrate, refractory black carbon and ammonium concentrations) of the suspected-melt layers with anomalously high $\mathrm{CH}_{4}$, because these chemical species were associated with isolated $\mathrm{CH}_{4}$ spikes in the NEEM-S1-2011 ice core (Rhodes et al., 2013) and GISP2 ice core (Mitchell et al., 2013, NH4+). In the Tunu13 record, there was no significant difference between chemical concentrations at depths coincident with anomalously high $\mathrm{CH}_{4}$ linked to melt layers and chemical concentrations at other depths (Fig. S3).

\subsection{Lock-in-zone $\mathrm{CH}_{4}$ variability}

Methane concentrations were measured continuously upcore into the lock-in zone for three ice cores: D4, Tunu13 and B40. We observed a marked increase in the amplitude of decimetre-scale variability and a gradual decrease in gas flow 
to the instrument through the lock-in zone (Fig. S4), similar to results produced by continuous $\mathrm{CH}_{4}$ analysis of the lockin zones in NEEM-2011-S1 (Rhodes et al., 2013) and WAIS Divide (WDC05A, Mitchell et al., 2015) ice cores. The sharp increase in the amplitude of high-frequency variability by up to 10-fold makes the base of the lock-in zone (close-off depth) easily recognisable in continuous $\mathrm{CH}_{4}$ data. We estimate the close-off depth to be $82 \mathrm{~m}$ at $\mathrm{D} 4,73 \mathrm{~m}$ at Tunu13 and $95 \mathrm{~m}$ at B40, comparable to values from firn air field campaigns at the latter two sites (Tunu13: Butler et al., 1999; B40: Weiler, 2008). The D4 continuous $\mathrm{CH}_{4}$ data appear to encompass the entire lock-in zone.

Initial examination suggests that the magnitude of lockin zone $\mathrm{CH}_{4}$ variability varies significantly between cores (Fig. S4) but it is not possible to quantify the degree of ambient air contamination influencing our lock-in zone measurements, either from laboratory air $(\sim 1890 \mathrm{ppb})$ via interconnected open porosity or from post-coring bubble closure (Aydin et al., 2010). It is therefore difficult to quantify the influence of layered bubble trapping on lock-in zone $\mathrm{CH}_{4}$ variability. However, we have reason to believe that the proportion of ambient laboratory air versus air from the closed porosity may be low because continuous $\mathrm{CH}_{4}$ measurements of WAIS Divide lock-in zone samples conducted using the same analytical system were well replicated by discrete $\mathrm{CH}_{4}$ measurements (see Mitchell et al., 2015; Fig. S5). Furthermore, Mitchell et al. (2015) used $\delta^{15} \mathrm{~N}$ of $\mathrm{N}_{2}$ data measured on the WAIS Divide lock-in zone samples to calculate the proportion of air affected by post-coring bubble closure as $10.6 \pm 6.1 \%$; this value should be considered as an upper estimate as the core used in that study was stored for $\sim 6$ years prior to analysis.

\subsection{High-frequency non-atmospheric signals in mature ice}

\subsubsection{Observations}

In the mature ice phase below the close-off depth we observe significant decimetre-scale variability in the $\mathrm{CH}_{4}$ records of every ice core analysed. In each case, it is impossible that this high-frequency signal could have existed in the atmosphere at the ice sheet surface and survived the low-pass filter action of the firn - the gas age distribution widths (Table 1) are greater than the approximate signal periods. We initially focus in detail on only Tunu13 and B40 because these are the most complete records, with relatively little ice removed prior to analysis and few ambient air entry problems, both factors linked to the number of core breaks (Table S1).

A smoothing spline is subtracted from the $\mathrm{CH}_{4}$ record of each site to effectively remove the atmospheric signal (Fig. 3a and b, Tunu13 shown). The residual $\mathrm{CH}_{4}$ record contains a high-frequency, non-atmospheric signal and analytical noise (Fig. 3b). The mean peak-to-peak amplitude (see Supplement) of the residual high-frequency $\mathrm{CH}_{4}$ in the

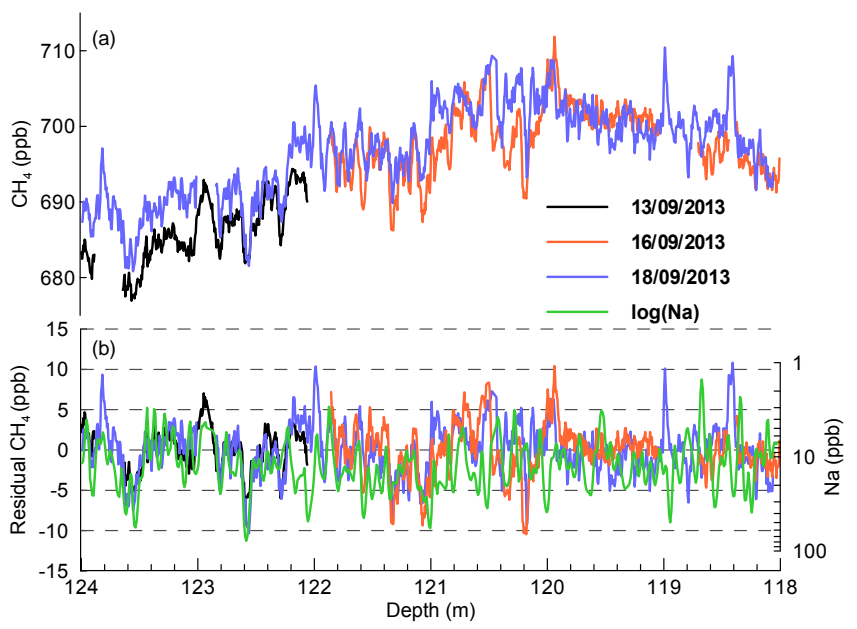

Figure 4. High-frequency $\mathrm{CH}_{4}$ variability in B40 (E. Antarctica) ice. Measured signals (a) and the residual (signal - spline fit)(b) are shown. Variability is replicated by analyses performed on the three dates displayed in legend (dd/mm/yyyy). Gas extraction was performed using a Membrana micromodule degasser on 13 September 2013 and an IDEX in-line degasser on 16 and 18 September 2013 (Table S1). Also shown on (b) is Na concentration, which typically co-varies with $\mathrm{Cl}$ concentration. Many of the anomalously low $\mathrm{CH}_{4}$ values are coincident in depth with relatively high $\mathrm{Na}$. This depth interval is dated as 1493-1583 AD gas age.

Tunu13 record from 987 to 1870 AD gas age is $5.3 \mathrm{ppb}$ (median is $3.7 \mathrm{ppb}$ ) and varies between 2 and $42 \mathrm{ppb}$. Variability of similar peak-to-peak amplitude and frequency observed along the NEEM ice core continuous $\mathrm{CH}_{4}$ profile was attributed to analytical system noise (Chappellaz et al., 2013). Here, we have confidence that we capture a high-frequency signal present above the analytical noise in some sections of the record because discrete $\mathrm{CH}_{4}$ measurements on the Tunu13 core conducted at $6 \mathrm{~cm}$ resolution also show substantial variability within each $15 \mathrm{~cm}$ depth section. $\mathrm{CH}_{4}$ concentrations in adjacent samples differ by up to $32 \mathrm{ppb}$, but more typically by $3.4 \mathrm{ppb}$, and reproduce some of the decimetre-scale changes resolved by the continuous measurements (Fig. 3c-e) $\mathrm{CH}_{4}$ oscillations captured by the discrete measurements are larger in amplitude than those in the continuous gas record because the continuous gas analysis system causes more signal smoothing than the discrete analysis (Stowasser et al., 2012; Table S1, Fig S2). The $5.3 \mathrm{ppb}$ mean peak-to-peak amplitude of this high-frequency nonatmospheric signal must therefore be a minimum estimate of the true signal in the ice.

A high-frequency, non-atmospheric signal in excess of analytical noise is also present in sections of the B40 continuous $\mathrm{CH}_{4}$ record and it is reproducible; we measured replicate ice core sticks on different days and were able to resolve very similar decimetre-scale features in ice samples from 114$120 \mathrm{~m}$ depth (Fig. 4). The sharp $\mathrm{CH}_{4}$ troughs at 122.8, 122.6, $122.3,121.3$ and $120.2 \mathrm{~m}$ are particularly well replicated and 
highly unlikely to be analytical artifacts. The mean peak-topeak amplitude of the high-frequency non-atmospheric signal in this section of the B40 record is $5.4 \mathrm{ppb}$ (median is $5.1 \mathrm{ppb})$.

\subsubsection{Evidence for layered bubble trapping}

Our results demonstrate that the quasi-annual variability previously observed in the ice phase of the NEEM-2011-S1 core (Rhodes et al., 2013) is not unique to NEEM or to Greenlandic ice. The question now is: what causes it? If it is an artifact of layered bubble trapping, as speculated for NEEM2011-S1, the observed decimetre-scale variability should respond in a predictable way to several factors that vary over time and between ice core sites. We therefore systematically examine our empirical data to assess the influence of each factor and judge whether any relationship is consistent with the mechanism of layered bubble trapping.

\section{Atmospheric $\mathrm{CH}_{4}$ growth rate}

Our conceptual model of layered bubble trapping predicts that the difference in $\mathrm{CH}_{4}$ concentration between adjacent layers $\left(\Delta \mathrm{CH}_{4}\right)$ should increase with the $\mathrm{CH}_{4}$ concentration gradient in the firn column, which is dictated by the atmospheric $\mathrm{CH}_{4}$ growth rate (Fig. 1). We can clearly observe this relationship in the Tunu13 record; amplitudes of the decimetre-scale $\mathrm{CH}_{4}$ oscillations are greatest when the atmospheric $\mathrm{CH}_{4}$ concentration shows a sustained trend of increase or decrease, particularly during the steep postIndustrial Revolution $\mathrm{CH}_{4}$ rise and the growth and decay in atmospheric $\mathrm{CH}_{4}$ concentrations associated with the prominent $\mathrm{CH}_{4}$ oscillation centered on $1550 \mathrm{AD}$ (Fig. 3b).

To explore this relationship quantitatively, we compare the $\mathrm{CH}_{4}$ growth rate to the standard deviation $(\sigma)$ of the highfrequency $\mathrm{CH}_{4}$ residual (data minus spline, as Fig. 3b) for moving windowed sections of the Tunu 13 record. Windows are 40 years in length and are calculated at 10-year interval. Strong linear relationships between $\mathrm{CH}_{4}$ growth rate and the magnitude of high-frequency variability are revealed for atmospheric $\mathrm{CH}_{4}$ growth and decay rates $>0.4 \mathrm{ppb} \mathrm{yr}^{-1}$ (Fig. 5e). The gradients of the linear relationships are similar in both cases (7-8 ppb $\sigma-\mathrm{CH}_{4} \mathrm{ppb} \mathrm{yr}^{-1}$ growth rate). At low growth rates $\left(<0.4 \mathrm{ppb} \mathrm{yr}^{-1}\right) \sigma-\mathrm{CH}_{4}$ values reflect the analytical precision of $1.7 \mathrm{ppb}$. The observation that $\sigma-\mathrm{CH}_{4}$ only increases beyond analytical noise at growth rate $>0.4 \mathrm{ppb} \mathrm{yr}^{-1}$ heavily implicates the mechanism of layered bubble trapping as the cause of the high-frequency $\mathrm{CH}_{4}$ signal because it requires sustained trend of change in atmospheric concentration to produce $\mathrm{CH}_{4}$ artifacts (Fig. 1). We therefore define high-frequency non-atmospheric $\mathrm{CH}_{4}$ variability in excess of analytical noise as "trapping signal".

This analysis was repeated on the high-frequency $\mathrm{CH}_{4}$ residual records from other ice cores: B40, NEEM-2011S1, D4 and NGRIP (Fig. 5a-d). For NGRIP, only data from
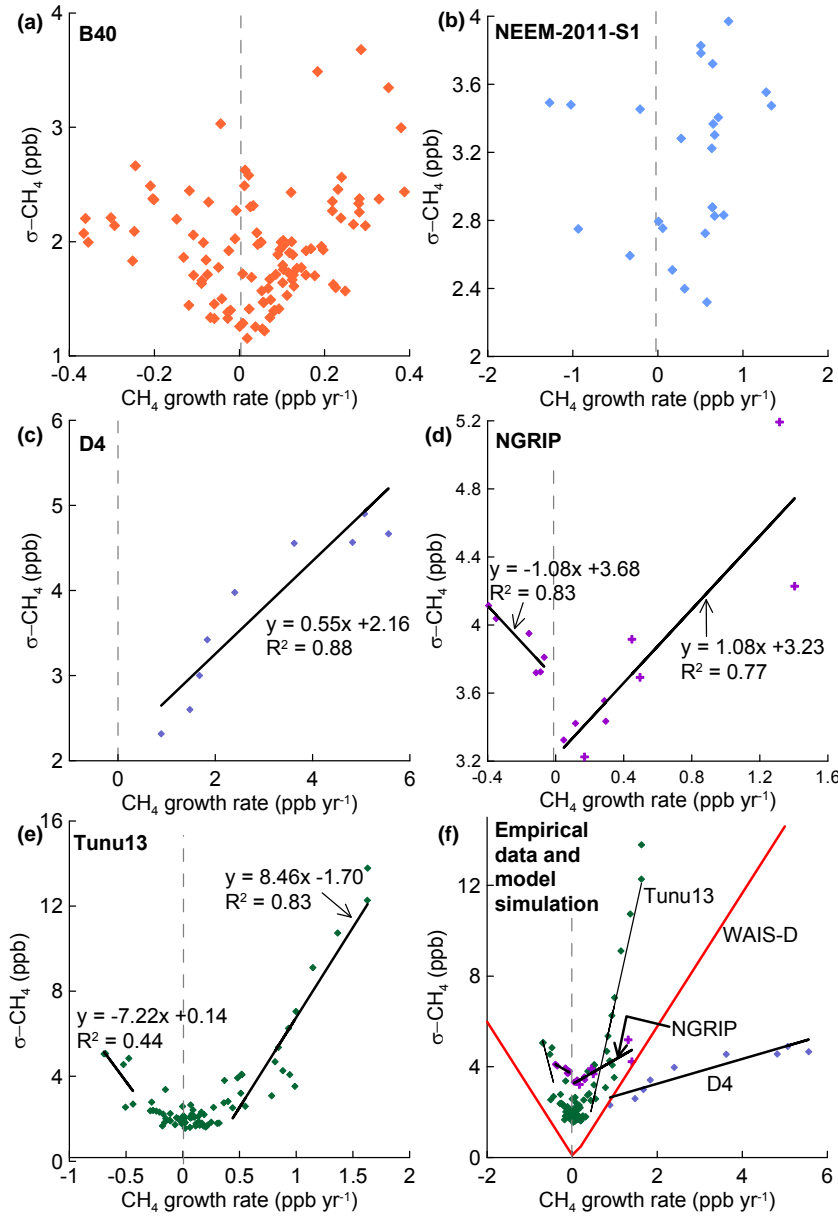

Figure 5. Relationship between $\mathrm{CH}_{4}$ growth rate and highfrequency $\mathrm{CH}_{4}$ variability $\left(\sigma-\mathrm{CH}_{4}\right)$ in the following ice cores: B40 (a), NEEM-2011-S1 (b), D4 (c), NGRIP (d), Tunu13 (e). $\sigma$ $\mathrm{CH}_{4}$ is calculated every 10 years for intervals of 40 years duration (except for 5 NGRIP data points (cross symbols), which are discrete 10 -year intervals with no overlap, due to poor core quality and discontinuous record). Linear regression of growth rate and $\sigma-\mathrm{CH}_{4}$ is displayed where appropriate. A linear fit is applied to Tunu13 and D4 data with growth rates $> \pm 0.4 \mathrm{ppb} \mathrm{yr}^{-1}$ and to NGRIP data with growth rates $> \pm 0.1 \mathrm{ppb} \mathrm{yr}^{-1}$. Panel (f) displays data from Tunu13, D4 and NGRIP with firn air transport model output for the WAIS Divide ice core (red).

1050-1240 and 1774-1860 AD (gas age) were used, the latter with a 10 years length window to avoid data gaps. For NEEM-2011-S1, data from 1450-1840 AD were used. Any 40 -year time window with a data gap $>5$ years duration was discarded from analysis. We note that the $\mathrm{CH}_{4}$ growth rate recorded in the ice core is not strictly equivalent to the atmospheric growth rate because firn-based smoothing may have caused some damping of the signal (Fig. 2). The B40 record is significantly affected by firn-based smoothing (Fig. S2), which reduces the growth rate captured by the ice core archive. The B40 record is also severely impacted by system- 
based smoothing (Fig. S2), which damps the trapping signal to within range of the analytical noise for much of the record, except the section displayed in figure 4 . The combination of these two effects destroys any relationship between atmospheric growth rate and amplitude of the high-frequency signal (Fig. 5a). There is also little sign of a relationship between growth rate and $\sigma-\mathrm{CH}_{4}$ in the NEEM-2011-S1 data (Fig. 5b) and we speculate this is the result of a more aggressive ambient air screening method applied by Rhodes et al. (2013) that may have removed real variability.

Results are more encouraging for D4 and NGRIP as both sites exhibit linear relationships between $\mathrm{CH}_{4}$ growth rate and the trapping signal magnitude (Fig. 5c and d). Both negative and positive growth rates at NGRIP exhibit the same gradient of change with $\sigma-\mathrm{CH}_{4}$. The consistency of results between sites is important for the identification of layered bubble trapping as the mechanism behind the high-frequency variability. Further support can be drawn from the CIC firn air transport model, which predicts a linear relationship between atmospheric growth rate and the $\mathrm{CH}_{4}$ trapping signal magnitude at WAIS Divide (red line, Fig. 5f). When the Tunu13, D4 and NGRIP data are all plotted on the same axes with the WAIS Divide model simulation (Fig. 5f), the gradient of the modelled linear relationship is within the range of gradients of our empirical data from three different Greenland ice core sites. Clearly, the $\mathrm{CH}_{4}$ trapping signal magnitude $\left(\sigma-\mathrm{CH}_{4}\right)$ does not have the same sensitivity to growth rate at all ice core sites; another factor is influencing $\mathrm{CH}_{4}$ variability, as we explore below.

For completeness we note that physics tells us that there can still be a tiny layered bubble trapping signal at zero growth rate due to the effect of gravity. As $\mathrm{CH}_{4}$ is lighter than air, gravity reduces the $\mathrm{CH}_{4}$ concentration with depth relative to the concentration in the atmosphere. Thus at zero growth rate there is still a $\mathrm{CH}_{4}$ gradient in the firn that can result in the generation of a trapping signal via layered gas occlusion. This also means that at positive atmospheric growth rates, the gravitational gradient must be overcome in order to generate $\mathrm{CH}_{4}$ oscillations related to layering. This is why the modelled WAIS Divide growth rate vs. $\sigma-\mathrm{CH}_{4}$ plot intersects the $\mathrm{x}$-axis at a slightly positive growth rate and $\sigma-\mathrm{CH}_{4}$ is predicted to be $0.11 \mathrm{ppb}$ at zero growth rate (Fig. $5 \mathrm{f}$ ). This effect is an order of magnitude smaller than the analytical noise and is not detectable.

\section{Accumulation rate}

At a constant atmospheric growth rate, the $\mathrm{CH}_{4}$ trapping signal amplitude produced by layered bubble trapping should be determined by the difference in age between the air trapped relatively early compared to younger air trapped relatively late ( $t_{2}$ minus $t_{1}$ on Fig. 1). One factor that will affect how quickly an adjacent layer is closed off is accumulation rate (A) - more new snow accumulation will cause layers to spend less time in the firn column reducing the time inter-
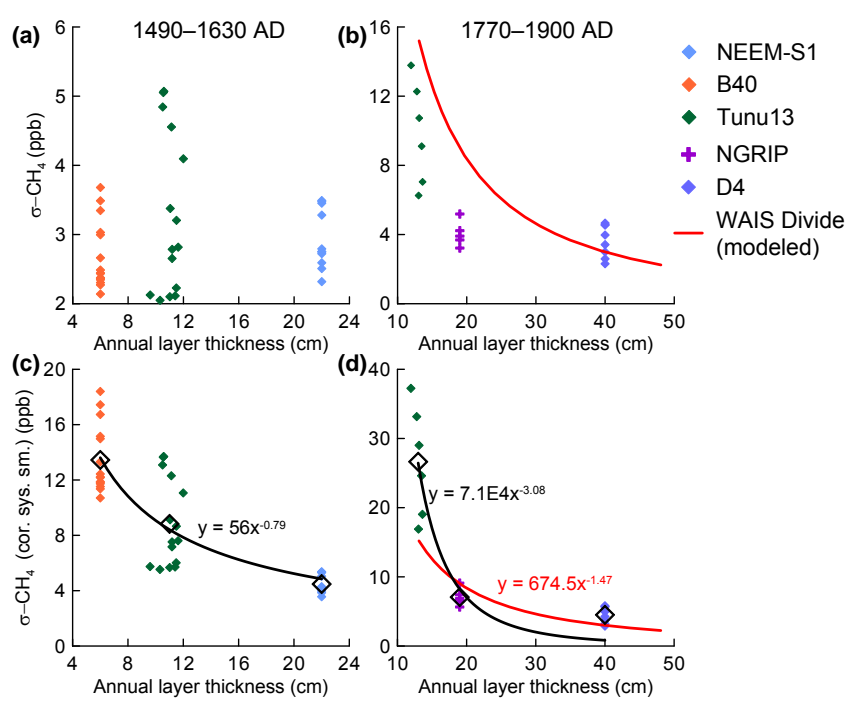

Figure 6. Relationship between accumulation rate and highfrequency $\mathrm{CH}_{4}$ variability. The vertical panels represent two time intervals: 1490-1630 AD (a) and 1770-1900 AD (b) for which high-resolution $\mathrm{CH}_{4}$ data are available from three ice cores with different accumulation rates. Note that the three clusters of data points for each time period do not represent the same ice cores in each case. The top row (a, b) displays $(\sigma)-\mathrm{CH}_{4}$ calculated every 10 years for intervals of 40 years duration as Fig. 5 (except for NGRIP data points on $(\mathbf{b}, \mathbf{d})$ that represent discrete 10-year intervals). The bottom row (c, d) displays $\sigma-\mathrm{CH}_{4}$ values adjusted (increased by $1.25-5$ depending on ice core) to correct for the damping effect of the continuous analytical system (Fig. S2). Mean values for each ice core on each panel are displayed (black diamonds) with power law relationships (black line). Also shown is the relationship between accumulation rate and $\sigma-\mathrm{CH}_{4}$ for WAIS Divide (at $2.5 \mathrm{ppb} \mathrm{yr}^{-1}$ atmospheric growth rate) as predicted by the CIC firn air transport model.

val over which layered bubble trapping can occur. We test this hypothesis by comparing the $\mathrm{CH}_{4}$ trapping signal magnitude in ice cores with different accumulation rates (Fig. 6a and $b$ ). Comparison is performed for two discrete time periods (gas age) for which we have good quality $\mathrm{CH}_{4}$ residual data (continuous and above analytical noise) from three cores, and we assume all three sites experienced the same atmospheric growth rate. As expected, there is a significant decrease in $\sigma-\mathrm{CH}_{4}$ with increasing accumulation rate for the 1770-1900 AD time period (Fig. 6), but the 1490-1630 AD interval shows no trend (Fig. 6a).

However, if we adjust the $\sigma-\mathrm{CH}_{4}$ values of each ice core to compensate for the differences in the smoothing effect of the analytical system, the results from the two time intervals become more consistent (Fig. 6c and d). To perform this adjustment, we assume that the high-frequency signal has an annual periodicity and consult the Bode plots generated from switching the analytical system between two gas standards, to determine what fraction of the original amplitude is retained by the system (Fig. S2). The nature of this relationship 
differs between time slices considered. An inverse relationship between $\sigma-\mathrm{CH}_{4}$ and annual layer thickness is identifiable for the 1490-1630 AD interval and a power law fit is applied, but a linear relationship would also be applicable here. A power law relationship is identifiable between annual layer thickness and $\sigma-\mathrm{CH}_{4}$ for the 1770-1900 AD time period, which has the greatest range of annual layer thickness and $\sigma-\mathrm{CH}_{4}$ values. These corrected data suggest that, at a fixed growth rate, an inverse relationship exists between accumulation rate and the magnitude of $\mathrm{CH}_{4}$ variability $(\sigma$ $\mathrm{CH}_{4}$ ). This is how we would expect $\mathrm{CH}_{4}$ trapping signal to respond to accumulation rate.

CIC firn air transport model simulations for WAIS Divide exhibit a similar power law relationship to the empirical data, whereby $\sigma-\mathrm{CH}_{4}$ is proportional to $1 / A^{1.47}$. The slope is the result of two separate effects. First, increasing $A$ decreases the time adjacent layers spend in the firn column, which by itself should cause $\mathrm{CH}_{4}$ trapping signal to scale as $1 / A$. Second, at increased $A$ the advective gas transport in the open pores is enhanced, and this reduces the $\mathrm{CH}_{4}$ gradient down the firn column. If bubbles are then trapped over the same depth range, the amplitude of $\mathrm{CH}_{4}$ variability will be reduced, and this effect appears to scale as $1 / A^{0.47}$ in the firn model. An important caveat is that the model assumes no change in the firn density profile with changing accumulation rate, which is unrealistic. However, the model does appear to capture a response of $\mathrm{CH}_{4}$ trapping signal to accumulation rate that is roughly comparable to that observable in the realworld data.

\section{Firn layering}

Another factor that should influence the amount of time that passes between early and late bubble closure is the degree of contrast between the physical properties of firn in adjacent layers. There is no doubt that the physical properties of firn ultimately control when a bubble is occluded, or a layer is completely sealed off. The relative importance of local density variability, firn microstructure, permeability and/or porosity in this process is actively debated. The traditional interpretation of density as the principal influence on bubble occlusion is being challenged (Gregory et al., 2014). However, we concentrate on the potential influence of local density variability in this section.

The controls on density layering in the firn are poorly understood, but a recent study suggests that variability near the firn-ice transition is higher at warmer, high accumulation sites (Hörhold et al., 2011). It is difficult to test the effects of density layering because we do not have the highresolution density information required to do so. However, we can use the CIC firn air transport model, which utilises high-resolution density data for the WAIS Divide ice core, to make a prediction. In these simulations, we define the density layering to be $\rho_{\text {layer }}=\rho-\langle\rho\rangle$ with the local firn densities $(\rho)$ as given by the high-resolution measurements, and the bulk density $(\langle\rho\rangle)$ as given by a spline fit to those data. We then run the model several times with a density profile that equals $\rho=\langle\rho\rangle+\alpha \rho_{\text {layer. }}$. By varying the scaling parameter $\alpha$ between 0 and 1.6 we can effectively control the magnitude of the firn density layering. As we would expect, no highfrequency $\mathrm{CH}_{4}$ trapping signal is produced in the absence of density layering ( $\alpha=0$; Fig. S5). When the magnitudes of the local density anomalies are halved ( $\alpha=0.5)$, the trapping signal amplitude decreases slightly more than 2-fold from 7.3 to $3.2 \mathrm{ppb}$. This effect is minor compared to that of accumulation rate or atmospheric growth rate. However, it may explain why interior Antarctic sites, like B40, which have less pronounced seasonality in density at the firn-ice transition compared to coastal Antarctic or Greenland locations (Hörhold et al., 2011) may show only a moderate trapping signal despite the extremely low accumulation rates.

\subsection{Layered gas trapping mechanism}

\subsubsection{Spatial and temporal information}

Having established that the high-frequency $\mathrm{CH}_{4}$ signal we observe in all the ice cores in this study shows characteristics consistent with the mechanism of layered gas trapping (Fig. 1), we are able to discern aspects of this physical process.

First, the $\mathrm{CH}_{4}$ trapping signal measured for the different ice core sites allows us to estimate the age difference between the air samples trapped in adjacent layers $\left(t_{2}-t_{1}\right.$ on Fig. 1). High-frequency $\mathrm{CH}_{4}$ residual data, corrected for system smoothing effects (Sect. 3.4.2) from the 1810 1860 AD time interval, which has an atmospheric growth rate of $1.5 \mathrm{ppb} \mathrm{yr}^{-1}$ (in D4 - the least susceptible record to firn-based smoothing of the atmospheric signal), suggest a gas age difference between adjacent layers of 23 years at Tunu13, 2.4 years at D4 and 5 years at NGRIP. These values can be compared to previously published estimates of 10 years for WAIS Divide (Mitchell et al., 2015), 12 years for NEEM-2011-S1 (Rhodes et al., 2013) and 2 years for Law Dome (Etheridge et al., 1992). Unsurprisingly, the gas age difference between adjacent layers is greater at lower accumulation sites. To negate the issue of smoothing associated with the analytical system, we also consider Tunu 13 discrete measurements, which show a maximum oscillation of $32 \mathrm{ppb}$ amplitude at an atmospheric growth rate of $1.5 \mathrm{ppb} \mathrm{yr}^{-1}$ (Fig. 3c). The age difference between layers in this case would be 21 years, which is very close to the estimate above.

Second, the frequency of $\mathrm{CH}_{4}$ oscillations resulting from layered bubble trapping should reflect the difference in depth, and therefore also ice age (not the age of the gas trapped inside the bubbles, as discussed above) between adjacent firn layers where bubbles are closed off at different times. To test this with our ice core data we perform multi-taper method (MTM) spectral analysis of the Tunu13, D4, NGRIP and B40 $\mathrm{CH}_{4}$ records (Fig. 7). Spectral analysis is performed in the ice 

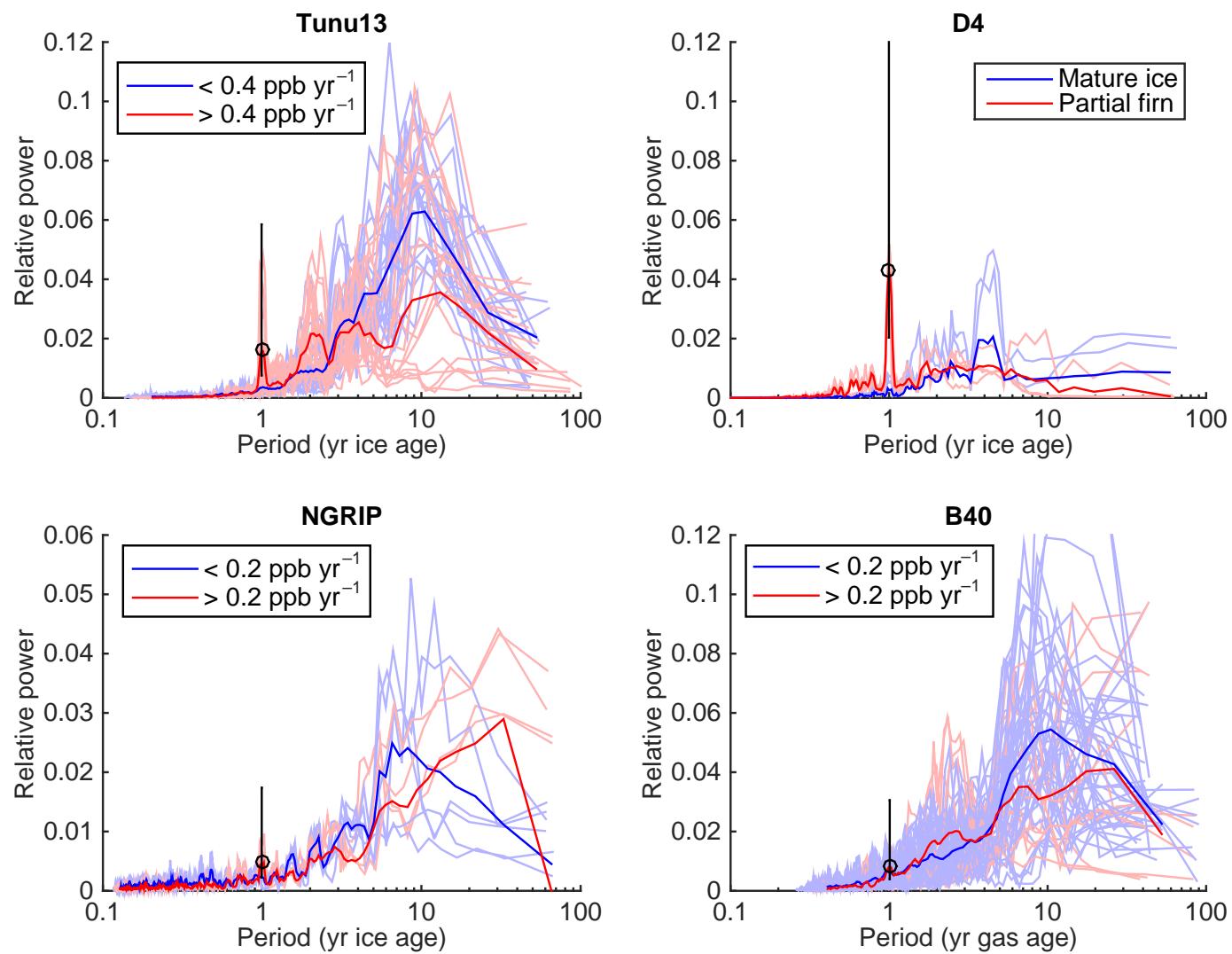

Figure 7. Multi-taper method (MTM) spectra of high-frequency, non-atmospheric residual $\mathrm{CH}_{4}$ variability of four ice cores. MTM was performed in the ice age domain using 2 tapers and $3^{\circ}$ of freedom. Each spectrum represents a 40 years window of data. For Tunu13, NGRIP and B40 each spectrum is colour-coded according to the $\mathrm{CH}_{4}$ growth rate of that data window. For D4, spectra are colour-coded according to whether or not the time window encompasses data from the lock-in zone ( $<82 \mathrm{~m}$ depth). All D4 spectra represent time windows of $\mathrm{CH}_{4}$ growth rate $>0.4 \mathrm{ppb} \mathrm{yr}^{-1}$. The bold lines represent averaged spectra for the low/high growth rate or mature ice/partial firn categories. The mean relative power at 1-year period is displayed (black open circles) with vertical lines representing the $90 \%$ confidence intervals for the averaged spectra (bold, red lines only) based on a chi-squared distribution. Spectral peaks are significant for Tunu13 and D4 because the confidence interval exceeds the background spectral noise.

age domain because we believe that physical properties of the firn/ice are ultimately responsible for the high-frequency artifacts recorded in the gas phase at the same depth. Prior to analysis, the data in each 40-year window (as Sect. 3.4.2) are interpolated to an even ice age spacing that is twice the median sample spacing and any windows containing data gaps $>2$ years are ignored. We then average the MTM spectra produced to generate mean spectra for sections of the record with relatively high or low growth rate, or in the case of D4, sections of the record encompassing only mature ice or some firn.

Sections of the Tunu13 record with $\mathrm{CH}_{4}$ growth rates $>0.4 \mathrm{ppb} \mathrm{yr}^{-1}$ exhibit spectral peaks at 1 -year period in the ice age domain and the averaged spectrum for growth rates $>0.4 \mathrm{ppb} \mathrm{yr}^{-1}$ has a significant 1 -year periodicity ( $95 \%$ confidence) (Fig. 7). By contrast, sections of the Tunu13 record with growth rates $< \pm 0.4 \mathrm{ppb} \mathrm{yr}^{-1}$ show no significant periodicity. The high accumulation Greenland ice core D4 shows an annual periodicity in $\mathrm{CH}_{4}$, but it only becomes signifi- cant when data from the lock-in zone are included (Fig. 7). NGRIP shows small spectral peaks at 1 -year period for 2 out of 4 time windows with growth rates $>0.2 \mathrm{ppb} \mathrm{yr}^{-1}$ but the peak in the averaged spectrum is not significant (Fig. 7). Again, NGRIP data sections with growth rates $<0.2 \mathrm{ppb} \mathrm{yr}^{-1}$ exhibit no periodicity. No significant periodicity is resolved in the B40 high-frequency residual $\mathrm{CH}_{4}$ record, potentially because any annual signal has been removed by analytical system smoothing.

The significant annual periodicity resolved in the Tunu 13 and D4 records during periods of relatively high growth rates strongly suggests that the mechanism of layered bubble trapping is linked to regular, seasonal variations in the physical properties of the firn pack, over a wide range of Greenland ice core site conditions. The quasi-annual high-frequency signal observed in mature NEEM-2011-S1 ice (Rhodes et al., 2013) could also be added to this list. We note that even if there is some ambient air contamination of D4 lock-in zone $\mathrm{CH}_{4}$ measurements, the wavelength of the $\mathrm{CH}_{4}$ oscil- 
lations in the lock-in zone should reflect the depth spacing of alternating layers with contrasting ratios of open to closed porosity, and therefore relatively more or less contamination (Fig. 7).

\subsubsection{Implications for bubble closure in the firn column}

The regular oscillations between relatively young and relatively old air trapped in the ice core air bubbles suggest that the early-closure layers ( $p_{\mathrm{h}}$ on Fig. 1) are not sealing layers which prevent vertical diffusion. In other words, some degree of open porosity/permeability must be maintained in these early-closure layers to allow relatively young air to diffuse down through the firn pack towards the late-closure layers ( $p_{1}$ on Fig. 1). This movement could be via vertical cracks or channels of open porosity tracking around isolated clusters of closed pores in the early-closure layers (Keegan et al., 2014). Furthermore, our results suggest that this situation must be maintained for upwards of 20 years at the Tunu 13 site.

The onset of the lock-in or non-diffusive zone (Sowers et al., 1992) is commonly believed to be linked to horizontally expansive sealing layers. Field measurements of firn air (air pumped from the open porosity in the firn) provide strong evidence for such sealing layers by demonstrating a lack of vertical mixing within the lock-in zone. For example, halocarbon tracers linked to anthropogenic industrial activity are effectively absent in the lock-in zone firn air at many sites (Butler et al., 1999; Severinghaus et al., 2010; Sturrock et al., 2002). To first order, the trapping signal we observe in the ice cores therefore suggests that significant bubble closure in the early-closure layers must occur above the lock-in depth, where vertical diffusion of the relatively young air required to form the regular $\mathrm{CH}_{4}$ oscillations is not impeded. However, we do not rule out a contribution to the trapping signal from within the lock-in zone because (a) some vertical pore connectivity in the lock-in zone is required to explain firn air observations at NEEM (Buizert et al., 2012) and (b) air content of mature ice is not consistent with fully sealing layers at the lock-in depth (Martinerie et al., 1992). Measurements of WAIS Divide lock-in zone samples suggest that much of the trapping signal is inherited from bubble trapping above the lock-in depth, below which the signal gradually becomes muted as vertical gas mixing is limited (Mitchell et al., 2015).

Our results suggest that the variations in local density and/or other related physical properties, such as open porosity or grain size (Gregory et al., 2014) maintain an imprint of annual variability towards the base of the firn column that is strong enough to produce regular layering in the firn, resulting in a $\mathrm{CH}_{4}$ trapping signal with a significant annual periodicity. It is still not clear precisely how and why layering in polar firn evolves with depth and time in the way that it does. Hörhold et al. (2012) suggested that "impurities" which exhibit an annual cycle in concentration may act to promote densification by softening the impurity-rich winter firn layers. Hörhold et al. (2012) reported positive correla-

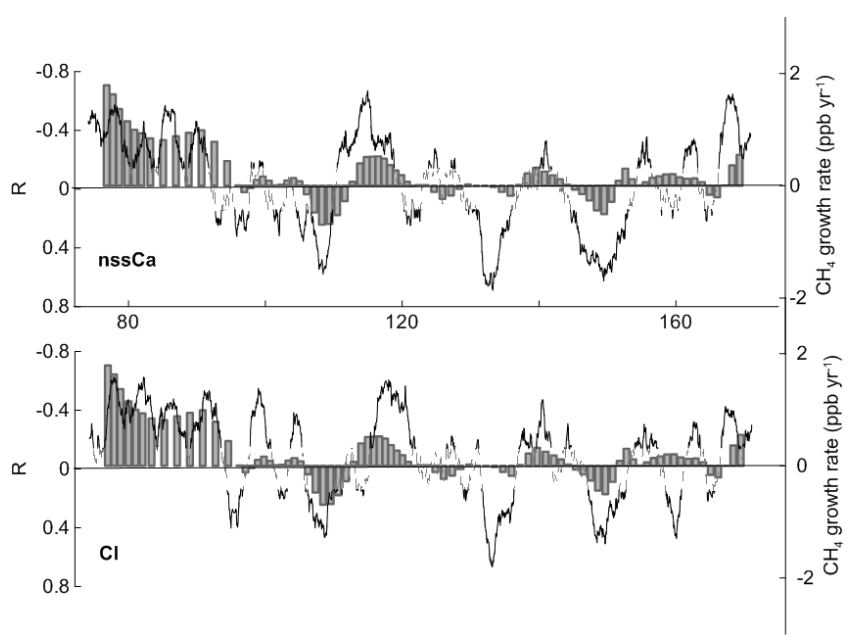

Figure 8. Moving window Spearman's rank correlation between concentrations of non-sea salt (nss) $\mathrm{Ca}$ and $\mathrm{Cl}$ and $\sigma-\mathrm{CH}_{4}$ in the Tunu13 ice core (line) compared to $\mathrm{CH}_{4}$ growth rate (vertical bars). Note the reverse direction of the left-hand $y$ axes. Significant $(p<0.05)$ (solid line) and non-significant (grey dashed line) coefficient of correlation $(R)$ values are plotted. Correlation is calculated for non-overlapping, $2 \mathrm{~m}$ length windows (using $0.5-5 \mathrm{~m}$ length windows produces similar results). The $\sigma-\mathrm{CH}_{4}$ time series is resampled to the depth spacing of chemistry data $(1 \mathrm{~cm})$ so $n=200$ for each window.

tions between soluble calcium $\left(\mathrm{Ca}^{2+}\right)$ concentration and local density but their choice of $\mathrm{Ca}^{2+}$ was not supported by any causal physical link between $\mathrm{Ca}^{2+}$ and densification rate. Ensuing work suggested that chloride $\left(\mathrm{Cl}^{-}\right)$and fluoride $\left(\mathrm{F}^{-}\right)$ were more likely candidates to drive densification at NEEM (Fujita et al., 2014), drawing on early experiments which detail how substitution of $\mathrm{Cl}^{-}$and $\mathrm{F}^{-}$ions into the ice lattice promotes dislocations and causes a softening effect (Jones, 1967; Nakamura and Jones, 1970). A subsequent study confirms these ideas by demonstrating their application to the Dome Fuji ice core (Fujita et al., 2016). It is important to note that Fujita et al. $(2016,2014)$ also invoke a second, independent process that contributes to densification which involves textural effects and is related to depositional conditions.

Our data cannot resolve this issue, but we can use the chemical concentrations measured as a proxy for local density, assuming that winter/spring chemical species like $\mathrm{Ca}$ and $\mathrm{Cl}$ are enriched in the relatively dense layers. In the Tunu13 ice core, concentrations of $\mathrm{Ca}$ and $\mathrm{Cl}$ show significant negative correlation $(p<0.05)$ with $\mathrm{CH}_{4}$ anomalies when growth rates are positive (Fig. 8). A similar relationship is observable for the short section of the B40 core with significant $\mathrm{CH}_{4}$ trapping signal, using $\mathrm{Na}$ in place of $\mathrm{Cl}$ in this instance because it is easier to measure at very low concentrations (Fig. 4b). These observations confirm the seasonality of layered gas trapping that we have assumed - $\mathrm{Ca}$ and Cl-rich, dense, layers trap air earlier, preserving a relatively low $\mathrm{CH}_{4}$ concentration when atmospheric $\mathrm{CH}_{4}$ is increasing, 
and vice versa. Correlation between impurity levels in the ice and $\mathrm{CH}_{4}$ anomalies does not signify a causal link between them. It makes sense that the correlation between ice chemistry and $\mathrm{CH}_{4}$ is stronger at high growth rates because the trapping signal produced at these times has a relatively high amplitude and an annual periodicity. What is more interesting is that the sign of the correlation coefficient between $\mathrm{Ca}$ or $\mathrm{Cl}$ and the high-frequency $\mathrm{CH}_{4}$ signal switches when $\mathrm{CH}_{4}$ growth rate is negative rather than positive (Fig. 8). When atmospheric $\mathrm{CH}_{4}$ is decreasing, a Ca-Cl-rich layer that closes off early will trap air with a relatively high $\mathrm{CH}_{4}$ concentration. This is an important final piece of evidence to attribute the high-frequency $\mathrm{CH}_{4}$ signal in ice cores to layered bubble trapping.

\section{Summary}

\subsection{Methane artifacts related to melt layers}

We have demonstrated that narrow, isolated peaks in $\mathrm{CH}_{4}$ concentration in the Tunu13 ice core record are located at depths coincident with bubble-free layers assumed to be melt layers. $\mathrm{CH}_{4}$ measurements on discrete ice samples enabled us to confidently link melt layers and $\mathrm{CH}_{4}$ enrichment, circumventing the complication of potential ambient air contamination from the continuous-flow system. These findings contrast with our previous study (Rhodes et al., 2013), in which we found no melt layers associated with anomalous $\mathrm{CH}_{4}$ signals in the NEEM-2011-S1 core, but are in agreement with published data showing trace gas enrichment across melt layers in the Dye 3 (Greenland) ice core (NEEM community members, 2013; Neftel et al., 1983). Furthermore, we confirm this and earlier work (Campen et al., 2003; NEEM community members, 2013) suggesting that dissolution of $\mathrm{CH}_{4}$ in the liquid phase cannot account for the full magnitude of $\mathrm{CH}_{4}$ enrichment in melt layers, suggesting, but not proving, that biological activity may be in part responsible for the observed $\mathrm{CH}_{4}$ enrichment. Additionally, we find no significant relationships between the anomalously high $\mathrm{CH}_{4}$ levels at melt layer depths and concentrations of chemical species $\left(\mathrm{NH}_{4}^{+}, \mathrm{rBC}\right.$ or $\left.\mathrm{NO}_{3}^{-}\right)$present in the ice phase of the Tunu13 ice core.

In the absence of a systematic, reliable methodology to confidently distinguish between elevated in situ $\mathrm{CH}_{4}$ signals and ambient air contamination, this study can only contribute limited information regarding the potential for biological in situ production of methane in polar ice. The implications of biological in situ production in polar ice are so far-reaching (Priscu and Hand, 2010) that it deserves further investigation by a dedicated multi-disciplinary project. Continuous trace gas analysis is an effective tool for screening cores to identify depth ranges with interesting signals but further analysis including $\delta^{13} \mathrm{CH}_{4}$, organic species and meticulous microbiological characterisation is needed.

\subsection{Methane artifacts resulting from layered bubble trapping}

This study uses high-resolution continuous $\mathrm{CH}_{4}$ data from five Late Holocene ice cores to demonstrate that layered bubble trapping causes high-frequency (decimetre-scale) oscillations in the $\mathrm{CH}_{4}$ record of mature ice from both Antarctica and Greenland when there is a sustained positive or negative trend in atmospheric growth rate. This trapping signal has been reproduced by discrete and continuous $\mathrm{CH}_{4}$ measurements and cannot reflect atmospheric history because firnbased smoothing processes would have removed it.

Using empirical data supported by firn air transport model simulations we demonstrate that the $\mathrm{CH}_{4}$ trapping signal responds in predictable ways to atmospheric growth rate and site-specific factors, particularly accumulation rate. The amplitude of the $\mathrm{CH}_{4}$ trapping signal increases with atmospheric growth rate and seasonal density contrasts, and decreases with accumulation rate. The layered bubble trapping signal in two Greenland ice core records has a significant annual periodicity, demonstrating that the seasonal contrasts in firn physical properties which develop above the firn-ice transition are regular and uniform enough to generate periodic $\mathrm{CH}_{4}$ artifacts.

\section{Implications}

\subsection{Implications for future ice core trace gas analysis}

- As resolution and precision of analytical techniques improve, analysts need to be aware that non-atmospheric, high-frequency signals are present in ice core trace gas records resulting from enrichment associated with melt layers and variability related to layered bubble trapping.

- Careful choices regarding discrete sample size and dimension, and post-processing of continuous data sets are required to avoid misinterpretation. Analysts should integrate trace gas data over multiple annual layers to smooth out the trapping signal, paying particular attention to time periods of relatively high atmospheric $\mathrm{CH}_{4}$ growth rate. Isolated anomalous $\mathrm{CH}_{4}$ signals should be anticipated at sites where surface melt is possible. These considerations are especially relevant for studies of the inter-polar gradient (e.g., Mitchell et al., 2013) because the absolute concentrations are so important to the conclusions reached.

- The magnitude of $\mathrm{CH}_{4}$ trapping signal within an ice core record or in a time slice can be predicted using a firn air transport model adapted for the purpose (Mitchell et al., 2015), provided information about the local density variability at the site is known. Density information from the firn could plausibly be extrapolated to Holocene ice but not to ice from widely different climatic conditions. If variability in chemical concentra- 
tions or impurities recorded in the ice phase could somehow be interpreted as a proxy for local density variability, this could help to inform modelling efforts. This study presents only an incremental step towards utilising chemistry records in this way.

\subsection{Implications for our understanding of gas trapping}

- Our empirical data demonstrate that layered gas trapping is driven by highly regular (seasonal) variations in the physical properties of layered firn, as suggested by Martinerie et al. (1992). Whether local density or some other closely-related property is primarily responsible for driving this seasonal variability in bubble occlusion is not clear.

- The regular $\mathrm{CH}_{4}$ oscillations of the trapping signal indicate that significant bubble closure must occur in the early-closure layers above the lock-in depth. Vertical diffusion though early-closure layers must be maintained for several years (our observations suggest up to 20 years) to allow relatively young air to become trapped in late-closure layers below.

- Despite the many bubble-free layers observed in the Tunu13 ice core, we do not find evidence of fully "sealing layers" above the lock-in zone - there is no major departure from the relationship between trapping signal and linear atmospheric growth rate (Fig. 5). Such a layer has only been observed previously in the Law Dome DE08-2 ice core; this thick melt layer caused an $80 \%$ reduction in gas diffusion (Trudinger et al., 1997). A recent examination of bubble-free layers in the WAIS Divide core also found no evidence for significant impact on gas transport (Orsi et al., 2015).

- The layered bubble trapping process has the effect of broadening the modelled gas age distribution of the air in ice cores, relative to a model scenario without layered bubble trapping but the same prescribed firn air diffusivity profile. Age distributions in realistic models of nonlayered firn compared to layered firn that capture the effect of layering on the diffusivity have yet to be studied, as far as we are aware. However, in nature, the presence of firn layering presumably leads to the formation of a lock-in zone, which causes a narrowing of the gas age distribution by limiting vertical diffusion. The net effect of firn layering is therefore likely to be a reduction in the width of the gas age distribution of air trapped in ice cores. (Mitchell et al., 2015).

An open question generated by this study is the following: why do the high-frequency oscillations in $\mathrm{CH}_{4}$ concentration increase sharply in amplitude across the transition from mature ice into the lock-in zone (Sect. 3.3)? The findings of Mitchell et al. (2015) suggest that contamination from ambient air is relatively low in continuous data from the lock-in zone and not enough to account for the 10-fold amplitude increase. So, if $\mathrm{CH}_{4}$ variability in the lock-in zone and in the mature ice phase are both related to layered bubble trapping, what causes the discontinuity? Could it be that drilling and cutting the ice samples inherently influences the observations by re-opening centimetre-scale pore clusters that were already closed off from the atmosphere? It may be that the only way to resolve this question is to devise a way to eliminate firn air alteration caused by both ambient air contamination and the re-opening of pores, perhaps by analysing trace gases across the lock-in zone to mature ice transition in situ.

\section{Information about the Supplement}

Data produced by this study are available to download in the Supplement. Data will also be made available on the NSF Arctic Portal www.arcticdata.io.

\section{The Supplement related to this article is available online at doi:10.5194/cp-12-1061-2016-supplement.}

Acknowledgements. This work was supported by US National Science Foundation (NSF) grants 1204172, 0944552, 1204176 and 0909541 and NSF Partnerships in International Research and Education (PIRE) Grant 0968391. This work was additionally supported by the French ANR program RPD COCLICO (ANR-10RPDOC-002-01) and received funding from the European Research Council under the European Community's Seventh Framework Program FP7/2007-2013 Grant Agreement \#291062 (project ICE\&LASERS). Jeffrey Severinghaus and David Etheridge provided insightful reviews that improved this manuscript. We thank Nathan Chellman, Daniel Pasteris, Larry Layman and Amber Zandanel for laboratory assistance, Nicole Rocco for Summit melt layer measurements, and Julia Rosen for use of OSU firn model. We are very grateful to Beth "Bella" Bergeron for her valuable expertise, leadership and hard work drilling the Tunu13 cores. Our field team received valuable assistance from CHM2HILL and Ken Borek Air. The NEEM project is directed by the Centre for Ice and Climate at the Niels Bohr Institute, Copenhagen and the US NSF OPP. It is supported by funding agencies and institutions in Belgium (FNRS-CFB and FWO), Canada (NRCan/GSC), China (CAS), Denmark (FIST), France (IPEV, CNRS/INSU, CEA and ANR), Germany (AWI), Iceland (RannIs), Japan (NIPR), Korea (KOPRI), The Netherlands (NWO/ALW), Sweden (VR), Switzerland (SNF), United Kingdom (NERC) and the USA (US NSF, OPP). We are grateful to the North Greenland Ice Core Project (NGRIP) for providing samples.

Edited by: T. van Ommen

\section{References}

Alley, B.: Concerning the deposition and diagenesis of strata in polar firn, J. Glaciol., 34, 283-290, 1988. 
Aydin, M., Montzka, S. A., Battle, M. O., Williams, M. B., De Bruyn, W. J., Butler, J. H., Verhulst, K. R., Tatum, C., Gun, B. K., Plotkin, D. A., Hall, B. D., and Saltzman, E. S.: Post-coring entrapment of modern air in some shallow ice cores collected near the firn-ice transition: evidence from CFC-12 measurements in Antarctic firn air and ice cores, Atmos. Chem. Phys., 10, 51355144, doi:10.5194/acp-10-5135-2010, 2010.

Buizert, C., Martinerie, P., Petrenko, V. V., Severinghaus, J. P., Trudinger, C. M., Witrant, E., Rosen, J. L., Orsi, A. J., Rubino, M., Etheridge, D. M., Steele, L. P., Hogan, C., Laube, J. C., Sturges, W. T., Levchenko, V. A., Smith, A. M., Levin, I., Conway, T. J., Dlugokencky, E. J., Lang, P. M., Kawamura, K., Jenk, T. M., White, J. W. C., Sowers, T., Schwander, J., and Blunier, T.: Gas transport in firn: multiple-tracer characterisation and model intercomparison for NEEM, Northern Greenland, Atmos. Chem. Phys., 12, 4259-4277, doi:10.5194/acp-12-4259-2012, 2012.

Buizert, C., Martinerie, P., Petrenko, V. V., Severinghaus, J. P., Trudinger, C. M., Witrant, E., Rosen, J. L., Orsi, A. J., Rubino, M., Etheridge, D. M., Steele, L. P., Hogan, C., Laube, J. C., Sturges, W. T., Levchenko, V. A., Smith, A. M., Levin, I., Conway, T. J., Dlugokencky, E. J., Lang, P. M., Kawamura, K., Jenk, T. M., White, J. W. C., Sowers, T., Schwander, J., and Blunier, T.: Corrigendum to "Gas transport in firn: multiple-tracer characterisation and model intercomparison for NEEM, Northern Greenland" published in Atmos. Chem. Phys., 12, 4259-4277, 2012, Atmos. Chem. Phys., 14, 3571-3572, doi:10.5194/acp-14-35712014, 2014.

Butler, J. H., Battle, M., Bender, M. L., Montzka, S. A., Clarke, A. D., Saltzman, E. S., Sucher, C. M., Severinghaus, J. P., and Elkins, J. W.: A record of atmospheric halocarbons during the twentieth century from polar firn air, Nature, 399, 749-755, doi:10.1038/21586, 1999.

Campen, R. K., Sowers, T., and Alley, R. B.: Evidence of microbial consortia metabolizing within a low-latitude mountain glacier, Geology, 31, 231-234, 2003.

Chappellaz, J., Stowasser, C., Blunier, T., Baslev-Clausen, D., Brook, E. J., Dallmayr, R., Faïn, X., Lee, J. E., Mitchell, L. E., Pascual, O., Romanini, D., Rosen, J., and Schüpbach, S.: Highresolution glacial and deglacial record of atmospheric methane by continuous-flow and laser spectrometer analysis along the NEEM ice core, Clim. Past, 9, 2579-2593, doi:10.5194/cp-92579-2013, 2013.

Etheridge, D., Pearman, G. I., and Fraser, P. J.: Changes in tropospheric methane between 1841 and 1978 from a high accumulation-rate Antarctic ice core, Tellus B, 282-294, 1992.

Faïn, X., Chappellaz, J., Rhodes, R. H., Stowasser, C., Blunier, T., McConnell, J. R., Brook, E. J., Preunkert, S., Legrand, M., Debois, T., and Romanini, D.: High resolution measurements of carbon monoxide along a late Holocene Greenland ice core: evidence for in situ production, Clim. Past, 10, 987-1000, doi:10.5194/cp-10-987-2014, 2014.

Fujita, S., Hirabayashi, M., Goto-Azuma, K., Dallmayr, R., Satow, K., Zheng, J., and Dahl-Jensen, D.: Densification of layered firn of the ice sheet at NEEM, Greenland, J. Glaciol., 60, 905-921, doi:10.3189/2014JoG14J006, 2014.

Fujita, S., Goto-Azuma, K., Hirabayashi, M., Hori, A., Iizuka, Y., Motizuki, Y., Motoyama, H., and Takahashi, K.: Densification of layered firn in the ice sheet at Dome Fuji, Antarctica, J. Glaciol., online first, 1-21, doi:10.1017/jog.2016.16, 2016.
Gregory, S. A., Albert, M. R., and Baker, I.: Impact of physical properties and accumulation rate on pore close-off in layered firn, The Cryosphere, 8, 91-105, doi:10.5194/tc-8-91-2014, 2014.

Hörhold, M. W., Kipfstuhl, S., Wilhelms, F., Freitag, J., and Frenzel, A.: The densification of layered polar firn, J. Geophys. Res., 116, F01001, doi:10.1029/2009jf001630, 2011.

Hörhold, M. W., Laepple, T., Freitag, J., Bigler, M., Fischer, H., and Kipfstuhl, S.: On the impact of impurities on the densification of polar firn, Earth Planet. Sc. Lett., 325-326, 93-99, doi:10.1016/j.epsl.2011.12.022, 2012.

Hou, S., Chappellaz, J., Raynaud, D., Masson-Delmotte, V., Jouzel, J., Bousquet, P., and Hauglustaine, D.: A new Himalayan ice core $\mathrm{CH}_{4}$ record: possible hints at the preindustrial latitudinal gradient, Clim. Past, 9, 2549-2554, doi:10.5194/cp-9-2549-2013, 2013.

Jones, S. J.: Softening of ice crystals by dissolved fluoride ions, Phys. Lett. A, 25, 366-367, doi:10.1016/0375-9601(67)907025, 1967.

Keegan, K., Albert, M. R., and Baker, I.: The impact of ice layers on gas transport through firn at the North Greenland Eemian Ice Drilling (NEEM) site, Greenland, The Cryosphere, 8, 18011806, doi:10.5194/tc-8-1801-2014, 2014.

Klein, K.: Variability in dry Antarctic firn - Investigations on spatially distributed snow and firn samples from Dronning Maud Land, Antarctica, PhD thesis, University of Bremen, Bremen, Germany, 2014.

MacFarling Meure, C., Etheridge, D., Trudinger, C., Steele, P., Langenfelds, R., van Ommen, T., Smith, A., and Elkins, J.: Law Dome $\mathrm{CO}_{2}, \mathrm{CH}_{4}$ and $\mathrm{N}_{2} \mathrm{O}$ ice core records extended to 2000 years BP, Geophys. Res. Lett., 33, L14810, doi:10.1029/2006GL026152, 2006.

Martinerie, P., Raynaud, D., Etheridge, D. M., Barnola, J.-M., and Mazaudier, D.: Physical and climatic parameters which influence the air content in polar ice, Earth Planet. Sc. Lett., 112, 1-13, doi:10.1016/0012-821X(92)90002-D, 1992.

McConnell, J. R., Lamorey, G. W., Lambert, S. W., and Taylor, K. C.: Continuous ice-core chemical analyses using inductively coupled plasma mass spectrometry, Environ. Sci. Technol., 36, 7-11, doi:10.1021/es011088z, 2002.

McConnell, J. R., Aristarain, A. J., Banta, J. R., Edwards, P. R., and Simões, J. C.: 20th-Century doubling in dust archived in an Antarctic Peninsula ice core parallels climate change and desertification in South America, P. Natl. Acad. Sci. USA, 104, 57435748, 2007.

Mitchell, L., Brook, E., Lee, J. E., Buizert, C., and Sowers, T.: Constraints on the Late Holocene anthropogenic contribution to the atmospheric methane budget, Science 342, 964-966, doi:10.1126/science.1238920, 2013.

Mitchell, L. E., Brook, E. J., Sowers, T., McConnell, J. R., and Taylor, K.: Multidecadal variability of atmospheric methane, 1000-1800 CE, J. Geophys. Res., 116, G02007, doi:10.1029/2010JG001441, 2011.

Mitchell, L. E., Buizert, C., Brook, E. J., Breton, D. J., Fegyveresi, J., Baggenstos, D., Orsi, A., Severinghaus, J., Alley, R. B., Albert, M., Rhodes, R. H., McConnell, J. R., Sigl, M., Maselli, O., Gregory, S., and Ahn, J.: Observing and modeling the influence of layering on bubble trapping in polar firn, J. Geophys. Res.Atmos., 120, 2558-2574, doi:10.1002/2014JD022766, 2015. 
Morville, J., Kassi, S., Chenevier, M., and Romanini, D.: Fast, lownoise, mode-by-mode, cavity-enhanced absorption spectroscopy by diode-laser self-locking, Appl. Phys. B-Lasers O., 80, 10271038, 2005.

Nakamura, T. and Jones, S. J.: Softening effect of dissolved hydrogen chloride in ice crystals, Scr. Metall., 4, 123-126, doi:10.1016/0036-9748(70)90176-6, 1970.

NEEM community members: Eemian interglacial reconstructed from a Greenland folded ice core, Nature, 493, 489-494, 2013.

Neftel, A., Oeschger, H., Schwander, J., and Stauffer, B.: Carbon dioxide concentration in bubbles of natural cold ice, J. Phys. Chem., 87, 4116-4120, doi:10.1021/j100244a025, 1983.

NGRIP community members: High-resolution record of Northern Hemisphere climate extending into the last interglacial period, Nature, 431, 147-151, 2004.

Orsi, A. J., Kawamura, K., Fegyveresi, J. M., Headly, M. A., Alley, R. B., and Severinghaus, J. P.: Differentiating bubble-free layers from melt layers in ice cores using noble gases, J. Glaciol., 61, 585-594, 2015.

Priscu, J. C. and Hand, K. P.: Microbial habitability of icy worlds, Microbe Mag. Am. Soc. Microbiol., 2010.

Rasmussen, S. O., Abbott, P. M., Blunier, T., Bourne, A. J., Brook, E., Buchardt, S. L., Buizert, C., Chappellaz, J., Clausen, H. B., Cook, E., Dahl-Jensen, D., Davies, S. M., Guillevic, M., Kipfstuhl, S., Laepple, T., Seierstad, I. K., Severinghaus, J. P., Steffensen, J. P., Stowasser, C., Svensson, A., Vallelonga, P., Vinther, B. M., Wilhelms, F., and Winstrup, M.: A first chronology for the North Greenland Eemian Ice Drilling (NEEM) ice core, Clim. Past, 9, 2713-2730, doi:10.5194/cp-9-2713-2013, 2013.

Rhodes, R. H., Faïn, X., Stowasser, C., Blunier, T., Chappellaz, J., McConnell, J. R., Romanini, D., Mitchell, L. E., and Brook, E. J.: Continuous methane measurements from a late Holocene Greenland ice core: Atmospheric and in-situ signals, Earth Planet. Sc. Lett., 368, 9-19, doi:10.1016/j.eps1.2013.02.034, 2013.

Rhodes, R. H., Brook, E. J., Chiang, J. C., Blunier, T., Maselli, O. J., McConnell, J. R., Romanini, D., and Severinghaus, J. P.: Enhanced tropical methane production in response to iceberg discharge in the North Atlantic, Science, 348, 1016-1019, 2015.

Rohde, R. A., Price, P. B., Bay, R. C., and Bramall, N. E.: In situ microbial metabolism as a cause of gas anomalies in ice, P. Natl. Acad. Sci. USA, 105, 8667-8672, doi:10.1073/pnas.0803763105, 2008.

Rosen, J. L., Brook, E. J., Severinghaus, J. P., Blunier, T., Mitchell, L. E., Lee, J. E., Edwards, J. S., and Gkinis, V.: An ice core record of near-synchronous global climate changes at the Bølling transition, Nat. Geosci., 7, 459-463, doi:10.1038/ngeo2147, 2014.

Sander, R.: Compilation of Henry's law constants (version 4.0) for water as solvent, Atmos. Chem. Phys., 15, 4399-4981, doi:10.5194/acp-15-4399-2015, 2015.
Schwander, J., Barnola, J. M., Andrié, C., Leuenberger, M., Ludin, A., Raynaud, D., and Stauffer, B.: The age of the air in the firn and the ice at Summit, Greenland, J. Geophys. Res., 98, 28312838, doi:10.1029/92jd02383, 1993.

Schwander, J., Sowers, T., Barnola, J. M., Blunier, T., Fuchs, A., and Malaizé, B.: Age scale of the air in the summit ice: Implication for glacial-interglacial temperature change, J. Geophys. Res., 102, 19483-19493, doi:10.1029/97jd01309, 1997.

Severinghaus, J. P., Albert, M. R., Courville, Z. R., Fahnestock, M. A., Kawamura, K., Montzka, S. A., Mühle, J., Scambos, T. A., Shields, E., Shuman, C. A., Suwa, M., Tans, P., and Weiss, R. F.: Deep air convection in the firn at a zero-accumulation site, central Antarctica, Earth Planet. Sc. Lett., 293, 359-367, doi:10.1016/j.eps1.2010.03.003, 2010.

Sigl, M., Winstrup, M., McConnell, J. R., Welten, K. C., Plunkett, G., Ludlow, F., Büntgen, U., Caffee, M., Chellman, N., Dahl-Jensen, D., Fischer, H., Kipfstuhl, S., Kostick, C., Maselli, O. J., Mekhaldi, F., Mulvaney, R., Muscheler, R., Pasteris, D. R., Pilcher, J. R., Salzer, M., Schüpbach, S., Steffensen, J. P., Vinther, B. M., and Woodruff, T. E.: Timing and climate forcing of volcanic eruptions for the past 2500 years, Nature, 523, 543-549, doi:10.1038/nature14565, 2015.

Sowers, T., Bender, M., Raynaud, D., and Korotkevich, Y. S.: $\delta^{15} \mathrm{~N}$ of $\mathrm{N}_{2}$ in air trapped in polar ice: A tracer of gas transport in the firn and a possible constraint on ice age-gas age differences, J. Geophys. Res.-Atmos., 97, 15683-15697, doi:10.1029/92JD01297, 1992.

Spahni, R., Schwander, J., Fluckiger, J., Stauffer, B., Chappellaz, J., and Raynaud, D.: The attenuation of fast atmospheric $\mathrm{CH}_{4}$ variations recorded in polar ice cores, Geophys. Res. Lett., 30, 1571, doi:10.1029/2003gl017093, 2003.

Stowasser, C., Buizert, C., Gkinis, V., Chappellaz, J., Schüpbach, S., Bigler, M., Faïn, X., Sperlich, P., Baumgartner, M., Schilt, A., and Blunier, T.: Continuous measurements of methane mixing ratios from ice cores, Atmos. Meas. Tech., 5, 999-1013, doi:10.5194/amt-5-999-2012, 2012.

Sturrock, G. A., Etheridge, D. M., Trudinger, C. M., Fraser, P. J., and Smith, A. M.: Atmospheric histories of halocarbons from analysis of Antarctic firn air: Major Montreal Protocol species, J Geophys. Res.-Atmos., 107, 4765, doi:10.1029/2002JD002548, 2002.

Trudinger, C. M., Enting, I. G., Etheridge, D. M., Francey, R. J., Levchenko, V. A., Steele, L. P., Raynaud, D., and Arnaud, L.: Modeling air movement and bubble trapping in firn, J. Geophys. Res.-Atmos., 102, 6747-6763, doi:10.1029/96JD03382, 1997.

Weiler, K.: On the composition of firn air and its dependence on seasonally varying atmospheric boundary conditions and the firn structure, PhD thesis, University of Bern, Bern, Switzerland, 2008 . 